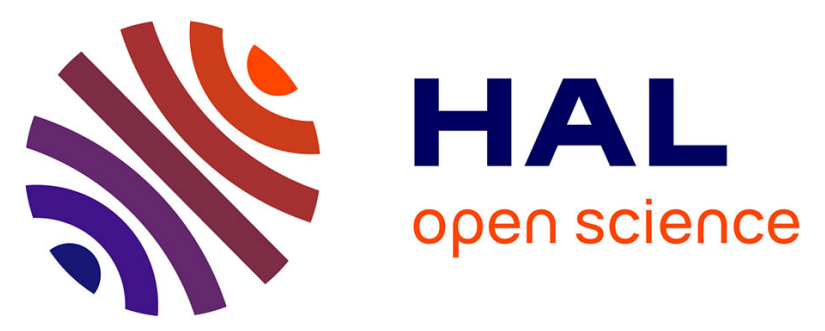

\title{
Green process technology for peroxycarboxylic acids: Estimation of kinetic and dispersion parameters aided by RTD measurements: Green synthesis of peroxycarboxylic acids
}

Sébastien Leveneur, Johan Wärnå, Kari Eränen, Tapio Salmi

\section{To cite this version:}

Sébastien Leveneur, Johan Wärnå, Kari Eränen, Tapio Salmi. Green process technology for peroxycarboxylic acids: Estimation of kinetic and dispersion parameters aided by RTD measurements: Green synthesis of peroxycarboxylic acids. Chemical Engineering Science, 2011, 66 (6), pp.1038-1050. 10.1016/j.ces.2010.12.005 . hal-02151572

HAL Id: hal-02151572

https://hal-normandie-univ.archives-ouvertes.fr/hal-02151572

Submitted on 27 Jan 2022

HAL is a multi-disciplinary open access archive for the deposit and dissemination of scientific research documents, whether they are published or not. The documents may come from teaching and research institutions in France or abroad, or from public or private research centers.
L'archive ouverte pluridisciplinaire HAL, est destinée au dépôt et à la diffusion de documents scientifiques de niveau recherche, publiés ou non, émanant des établissements d'enseignement et de recherche français ou étrangers, des laboratoires publics ou privés. 


\section{Green process technology for peroxycarboxylic acids: estimation of kinetic} and dispersion parameters aided by RTD measurements: green synthesis of

\section{peroxycarboxylic acids}

\section{Sébastien Leveneur ${ }^{a, b *}$, Johan Wärnå ${ }^{a}, K_{\text {Kri Eänen }}^{a}$, Tapio Salmi $^{a}$}

aLaboratory of Industrial Chemistry and Reaction Engineering, Process Chemistry Centre, Åbo Akademi University, Biskopsgatan 8, Fl-20500 Åbo/Turku, Finland.

bLSPC-Laboratoire de Sécurité des Procédés Chimiques, INSA Rouen, BP08, Avenue de l'Université, 76801 Saint-Étienne-du-Rouvray, France.

Tel: +33 2329566 54; Fax: +33 $2 \quad 32 \quad 95 \quad 66$ 96; E-mail: sebastien.leveneur@insa-rouen.fr

\section{ABSTRACT}

Synthesis of peroxypropionic and peroxyacetic acids from hydrogen peroxide and their carboxylic acids was carried out in a continuous fixed-bed reactor, demonstrating the concept of green process technology: biodegradable chemicals are made with the aid of heterogeneous catalysts. This reactor was constructed with several sampling locations along its length, allowing a better kinetic investigation. A profound study of the mean residence time distribution (RTD) was performed to analyze the behaviour of the flow pattern at different liquid flow rates and catalyst loadings by using step and impulse methods with different tracer molecules. It was found that impulse experiments with $\mathrm{HCl}$ as a tracer is the most reliable method to study the RTD because of this tracer does not interact with the catalyst. Based on the RTD study, it was demonstrated that the temperature (in the range $30-60^{\circ} \mathrm{C}$ ) and the catalyst distribution inside the reactor do not affect the 
flow pattern, but the ratio of the catalyst mass-to-liquid ratio affects the mean residence time and the liquid dispersion. Furthermore, it was shown that the presence of axial dispersion is negligible when the average particle diameter is less than $1.38 \mathrm{~mm}$, e.g., the Péclet number exceeds 100. The kinetic study was carried out at different mean residence times (from 10 to $55 \mathrm{~min}$ ), at different wet catalyst loadings (from 25 to $49 \mathrm{~g}$ ) and reactor temperatures (from 30 to $60^{\circ} \mathrm{C}$ ). Mathematical models comprising kinetic and dispersion parameters were developed to compare the estimated parameters obtained from the continuous fixed-bed reactor with the ones obtained from a batch reactor.

Keywords: Peroxycarboxylic acid, Kinetics, Fixed-bed reactor, Residence Time Distribution, Mathematical modelling, Cation exchange resin catalysts 


\section{Introduction}

The environmental impact and the safety aspects for the production of chemicals are the two main issues to ensure the sustainability of industrial production. Preventing the formation of waste products, suppressing the energy consumption, designing safer processes, utilizing non-toxic and non-hazardous chemicals, and optimizing the productivity are the main concerns of all the chemical companies. The concept of "Green Chemistry" introduced in the 1990's has provided methods and tools to take into account these issues for the scientific and industrial community. Later on, the concept of "green process technology" has been developed, emphasising the importance of continuous technology, use of nontoxic heterogeneous catalyst and driving at biodegradable products.

Oxidation reactions are fundamental in industry, but many of these reactions are carried out by using conventional heavy-metal oxidants, which form toxic waste, application of nitric acid which form the greenhouse gas $\mathrm{N}_{2} \mathrm{O}$; and utilization of molecular oxygen, which requires safety precautions and could cause overoxidation. According to Noyori (2007), an elegant way to surmount these problems is the use of aqueous hydrogen peroxide, as the oxidant hydrogen peroxide is a powerful oxidant. 
Among all these reactions carried out in the presence of hydrogen peroxide, the perhydrolysis of carboxylic acid can be an example of the application of green chemistry and green process technology. The reaction product is a peroxycarboxylic acid.

The market volume of peroxycarboxylic acids can be estimated to be some 10000 tonnes worldwide (Rüsch et al., 2002). Three domains of application can be distinguished: disinfecting agent, bleaching agent and as an intermediate in fine chemistry. All these applications are based on the oxidative properties of these compounds, due to the chemical bond

Several routes of the synthesis of peroxycarboxylic acids are available, such as oxygenation of the parent aldehyde (Phillips et al., 1958) or carboxylic acid (Cantieni, 1937). The reaction of carboxylic acid perhydrolysis is described by the following equation:

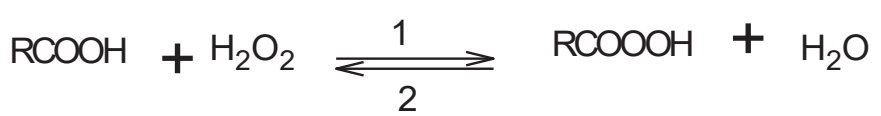

This reaction is reversible and requires the presence of an enhancing chemical species, an acid catalyst, since the carboxylic acid itself is usually a too weak acid to promote the reaction velocity.

Traditionally, this reaction is catalyzed by mineral acids, such as sulfuric acid leading to several drawbacks such as corrosion, threat for the environment and catalyst separation. Cation exchange resins have been found to be the most adequate catalysts for this reaction (Leveneur et al., 2009a, 2009b, 2009c; 
Hawkinson and Schitz, 1957; Musante et al., 2000). The great benefit is that the resins do not decompose the peroxide species. However, most of the previous studies reported in the open literature have been carried out in a batch reactor.

The research efforts concerning the perhydrolysis reactions in continuous reactors in the presence of heterogeneous catalysts are scarce (Saha et al., 2003). The objective of this paper is to demonstrate that the development of a continuous process concept based on the use of heterogeneous catalysts for manufacture of peroxycarboxylic acids is possible, and to provide a comparison with the kinetics obtained in batch and continuous modes. The second objective is to provide a profound study of the flow pattern by using different methods (step and impulse) and different tracer molecules. The final aim is to develop a model including kinetic and dispersion effects. 


\section{Experimental section}

2.1. Apparatus and experimental procedures

The chemical reaction and the residence time distribution (RTD) experiments were carried out in the same continuous reactor. However, the injection procedures were different. The reactor was set up in diagonal to ease the sampling and prevent back-mixing phenomenon.

\section{Perhydrolysis reaction}

A jacketed catalytic fixed-bed reactor consisting of catalyst layers and inert materials (for sampling) was used. The reactor was operated in the upflow mode to enhance the catalyst wetting, and put in a diagonal position. By inclining the reactor in such position, one could expect the formation of dead spaces or bypassing, which were not detected during the residence time distribution study. The main reasons for such setup were to ease the sampling, to diminish backmixing compared to a vertical reactor operating in upflow mode and to avoid the trapping of gas in case of peroxides decomposition (compared to a horizontal position). Samples were withdrawn from different positions in the reactor. Amberlite IR-120 was used as the heterogeneous catalyst. Fig. 1 presents a schematic view of the experimental setup. The length of the reactor was $60 \mathrm{~cm}$ and the internal diameter was $1.45 \mathrm{~cm}$.

\section{Here Figure 1.}


In a first stage, a mixture of carboxylic acid (propionic acid: Acros, 99 wt.\% or acetic acid: J.T.Baker 99-100 wt.\%) and hydrogen peroxide solution (Merck, 30 wt.\%) were mixed together in a separate storage vessel placed in a water bath. After 30 minutes (time to reach the desired reaction temperature), this mixture was fed to the continuous reactor through a pump. The experimental data for the kinetics modelling were obtained after three hours of time-on-stream, to safely operate under steady state conditions. Different amounts of catalyst and inert materials were used in the experiments as illustrated by Scheme 1 .

\section{Here Scheme 1.}

Table 1 shows the experimental conditions used while Table 2 shows the properties of quartz inert material and Amberlite IR-120 resin catalyst.

\section{Here Table 1.}

\section{Here Table 2.}

Residence time distribution

Pulse and step experiments were used to determine the residence time distribution (RTD) in the fixed-bed reactor. In general, the tracer molecule should have a similar structure to that of the reactant and the product molecules, without interfering with the catalyst. For the sake of comparison, acetic acid, propionic acid, hydrogen peroxide and hydrochloric acid were used as tracers. 
In case of pulse experiments, around $1-2 \mathrm{~g}$ of the solution at $0.02 \mathrm{M}$ of $\mathrm{HCl}, 1$ or 5 $\mathrm{M}$ of propionic acid was introduced at the inlet of the reactor during 2-5 s. The tracer experiments were carried out at two different temperatures: $30^{\circ} \mathrm{C}$ and $50^{\circ} \mathrm{C}$, and different flow rates. Step experiments were performed with two pumps connected to two batch vessels. One of the vessels contained the tracer dissolved in de-ionized water and the other one only deionised water. In both cases, the concentration of the tracer was followed on-line by conductivity, and the data were recorded 5 s intervals.

\subsection{Chemical analysis}

The liquid phase was analyzed off-line by titration with Greenspan and Mackellar methods (Greenspan and Mackellar, 1948). The concentration of hydrogen peroxide was determined by titration using a standard solution of ammonium cerium sulfate $(0.1 \mathrm{~N})$. The concentrations of carboxylic and peroxycarboxylic acids were determined by titration with an automatic titrator (Metrohm 751 GPD Titrino) using a standard solution of sodium hydroxide $(0.2 \mathrm{~N})$.

\subsection{Catalyst properties}

The ion exchange resins were washed with deionised water and filtered before introducing into the fixed-bed reactor. The properties of Amberlite IR-120 are summarized in Table 3 . It is a cation exchange resin with a styrene-divinyl benzene matrix bearing sulfonic acid groups. The catalyst was used in the form of beads. 


\section{Here Table 3.}

The tubular reactor was filled with wet catalyst, i.e., in a first stage the native catalyst was washed with deionised water, and then filtrated. 


\section{Results and discussions}

\subsection{Residence time distribution}

The study of the flow pattern (RTD) is an important issue of this work. The flow pattern investigation was mainly carried out with the reactor 4 (the presence of only one layer of catalyst) to find the most adequate method to measure RTD.

\subsubsection{Pulse experiments}

The pulse experiments were carried out with $\mathrm{HCl}$ and propionic acid.

$\mathrm{HCl}$ as a tracer

Hydrochloric acid was used because it is a strong electrolyte and does not interfere with the resin. Due the small concentration of the $\mathrm{HCl}$ solution along the reactor, the following relationship was used to determine its concentration at the outlet versus time,

$$
\sigma=\lambda \mathrm{c}
$$

where $\sigma$ is the measured conductivity $\left[\mathrm{S}_{\mathrm{m}} \mathrm{m}^{-1}\right], \mathrm{c}$ is the concentration $\left[\mathrm{mol} \cdot \mathrm{m}^{-3}\right]$ and $\lambda$ $\left[\mathrm{S} \cdot \mathrm{m}^{2} \cdot \mathrm{mol}^{-1}\right]$ is the molar conductivity. 
Fig. 2 displays the E-curves recorded at different flow rates at the reactor outlet (reactor 4). The function $E$ is defined as:

$$
\begin{aligned}
E(t) & =\frac{C(t)}{\text { Area under concentration of pulse versus tim }} \\
& =\frac{C(t)}{\sum C(t) \Delta t}
\end{aligned}
$$

\section{Here Fig.2.}

Fig. 2 shows that the distribution is symmetric. The mean residence time $\overline{\mathrm{t}}$ was calculated from the experimental data as follows:

$\overline{\mathrm{t}}=\frac{\sum_{\mathrm{i}} \mathrm{t}_{\mathrm{i}} \mathrm{C}_{\text {pulse },} \Delta \mathrm{t}_{\mathrm{i}}}{\sum_{\mathrm{i}} \mathrm{C}_{\text {pulse, },} \Delta \mathrm{t}_{\mathrm{i}}}$

On the other hand, the mean residence time is related to the volumetric flow rate

$(\mathrm{F})$

$$
\overline{\mathrm{t}}=\frac{\mathrm{V}_{\mathrm{L}}}{\mathrm{F}}
$$

where $V_{L}$ represents the void volume of the tube reactor, i.e. the liquid volume. Fig. 3 represents the flow rate versus the inverse of the mean residence time at $50^{\circ} \mathrm{C}$. The mean residence time was obtained from Eq. (3). The plot is a straight line, as reported.

\section{$\underline{\text { Here Fig. } 3}$}


In the case of the reactor 4 , the flow pattern is equal to $34.22 \mathrm{ml}$ as depicted by Fig. 3. Levenspiel (1999) has introduced the dimensionless group $\frac{\mathrm{D}}{\mathrm{uL}}$, where $\mathrm{D}$ $\left[\mathrm{m}^{2} \cdot \mathrm{s}^{-1}\right]$ is the axial dispersion coefficient, $L$ the length of the vessel $[\mathrm{m}]$ and $u$ the superficial velocity $\left[\mathrm{m}_{\mathrm{s}} \mathrm{s}^{-1}\right]$. This parameter is called vessel dispersion number, and measures the extent of the axial dispersion. The reciprocal value of $D /(\mathrm{UL})$ is called Péclet number $(\mathrm{Pe})$.

Thus, $\frac{\mathrm{D}}{\mathrm{uL}} \rightarrow 0$ negligible dispersion, hence plug flow and $\frac{\mathrm{D}}{\mathrm{uL}} \rightarrow \infty$ large dispersion, hence mixed flow.

The parameter $\mathrm{D} /(\mathrm{uL})$ can be determined from the experimentally recorded mean residence time $\left(\overline{\mathrm{t}}^{2}\right)$ and variance (Var).

$\frac{\operatorname{Var}}{\overline{\mathrm{t}}^{2}}=2\left(\frac{\mathrm{D}}{\mathrm{uL}}\right)$

The amount of catalyst and inert material was similar between reactors 1 and 4 , but their distributions along the reactor were different. Fig. 4 shows the evolution of $\overline{\mathrm{t}}$ at different flow rates for reactors 1 and 4 .

\section{Here Fig. 4.}

Table 4 shows the value of the parameter $\mathrm{D} /(\mathrm{uL})$ and the Pé number for each reactor at different flow rates. It can be concluded that the axial dispersion effect is rather negligible in both cases, since the Péclet number obtains a high value, in most cases exceeding 100. 


\section{Here Table 4.}

Fig. 4 and Table 4 confirm that the flow pattern does not depend on the distribution of the catalyst and the inert material. The RTD measurements carried out at $30^{\circ} \mathrm{C}$ gave the same value of $\overline{\mathrm{t}}$ and $\mathrm{D} / \mathrm{uL}$; so the flow pattern does not depend on the temperature within the temperature range of $30-50^{\circ} \mathrm{C}$.

\section{Here Fig. 5.}

Fig. 5 presents the evolution of the mean residence time $\overline{\mathrm{t}}$ with the flow rate. It is a clear tendency that increasing the catalyst loading leads to a decrease of the liquid volume in the reactor. Indeed, by decreasing the amount of catalyst loading, the average diameter $\bar{d}_{p}$ increases because the amount of glass balls increases.

In case of reactors 1,2 and 4, the axial dispersion effect was negligible during the impulse measurement carried out with the $\mathrm{HCl}$ solution. However, in case of reactor 3 (lowest catalyst loading), axial dispersion was noticeable. Fig. 6 shows the E-curves for different flow rates, and the presence of a tail in the curve is visible at different flow rates.

\section{Here Fig. 6.}

The parameter D/uL is less than 0.01 for reactor 1,2 and 4 , but in the case of reactor 3 this parameter is slightly higher as shown by Table 5 . 


\section{$\underline{\text { Here Table } 5}$}

According to the experimental setup, the measurement was done in closed conditions. Thus, to evaluate $\mathrm{D} /(\mathrm{uL})$, the following equation valid for axial dispersion model was used:

$$
\frac{\sigma^{2}}{\overline{\mathrm{t}}^{2}}=2\left(\frac{\mathrm{D}}{\mathrm{uL}}\right)-2\left(\frac{\mathrm{D}}{\mathrm{uL}}\right)^{2}\left[1-\mathrm{e}^{-\mathrm{uL} / \mathrm{D}}\right]
$$

According to Chander et al. (2001), the Pé number is influenced by the size of the particles inside a fixed-bed reactor. During their experiments, they have noticed that axial dispersion is significant with particle diameter higher than 1.1 $\mathrm{mm}$. By calculating the average particle diameter (Table 8), one can notice that the presence of axial dispersion appears when the diameter of the particle is bigger, i.e. the diameter of the particle is equal to $1.38 \mathrm{~mm}$ for reactor 3 and lower than $1.14 \mathrm{~mm}$ for the other reactors.

Propionic acid as a tracer

The steric hindrance of $\mathrm{H}_{2} \mathrm{O}_{2}$ and $\mathrm{HCl}$ molecule is similar, but not for propionic or acetic acid. Propionic acid is a weaker electrolyte than $\mathrm{HCl}$, for that reason a more concentrated solution than $\mathrm{HCl}$ solution was used. Due to the high concentration of the carboxylic acid solution used, Eq. (1) cannot be used for the interpretation of the primary data. However, the exit age distribution curve can be calculated by considering the intensity of the signal as follow: 


$$
\begin{aligned}
\mathrm{E} & =\frac{\sigma(\mathrm{t})}{\text { area under conductivity versustime }} \\
& =\frac{\sigma(\mathrm{t})}{\sum \sigma(\mathrm{t}) \Delta \mathrm{t}}
\end{aligned}
$$

Two concentrations of propionic acid were used, 1 and $5 \mathrm{M}$. The results obtained with a solution of $1 \mathrm{M}$ of propionic acid gave better results, i.e., the distribution is close to Gaussian. In view of the journal space limitation, only the E-curves for concentration at $1 \mathrm{M}$ is shown (Fig. 7).

\section{Here Fig. 7.}

By using propionic acid as a tracer molecule, the estimated volume of liquid in the reactor is between $60-63 \mathrm{ml}$, which is higher than the one determined by $\mathrm{HCl}$ solution. The difference of RTD for $\mathrm{HCl}$ and propionic acid is due to the fact that propionic acid adsorbs to some extent on the active site of the catalyst (Leveneur et al., 2009d), and thus takes a longer time to be released from the reactor.

Table 6 displays the value of the dispersion parameters calculated with RTD experiments performed at different propionic acid concentrations. One can notice that the estimated value of Pé is low, which might be due to the adsorption of propionic acid on the resin.

Here Table 6. 


\subsubsection{Step response experiments}

Step response experiments were used to check whether there are any phenomena of hysteresis by using $\mathrm{HCl}$ or propionic acid as a tracer molecule. Positive and negative step experiments were carried out.

Step response experiments with $\mathrm{HCl}$

The F-curve obtained from the relation:

$\mathrm{F}=\frac{\mathrm{C}_{\text {step }}}{\mathrm{C}_{\text {max }}}$

where $\mathrm{C}_{\max }$ is the tracer concentration at steady state.

Here Fig. 8.

Fig. 9 displays the evolution of the mean residence time by using positive and negative step methods.

Here Fig. 9.

Fig. 9 indicates that there is a difference between the positive and negative step, essentially at high flow rates. 
Step response experiments with propionic and acetic acid

Step experiments with a solution of acetic acid concentrated at $1.2 \mathrm{~mol} / \mathrm{l}$ and propionic acid at $0.98 \mathrm{~mol} / \mathrm{l}$ were carried out. The presence of a hysteresis effect was higher than with hydrochloric acid, which suggests that carboxylic acids are not the more adequate molecules to determine RTD in the present case.

\subsubsection{Conclusions from the RTD studies}

Fig. 10 depicts the flow rate versus the mean residence time with different methods (step and pulse) and tracer molecules.

\section{Here Fig. 10.}

Fig. 10 shows that the RTD profile given by step experiments with a solution of propionic and acetic acid at $7 \mathrm{wt} . \%$ are similar. This is due the similarity of both molecules regarding the adsorption properties, and confirms that these molecules cannot be used as tracers to determine the RTD.

The measurement of the residence time distribution by impulse method with carboxylic acid gave different results than the pulse experiment with hydrochloric acid or the step method with carboxylic acid. Due to the fact that the adsorption of carboxylic acid on the resins can interfere with a real measurement of the RTD, 
the mean residence $\overline{\mathrm{t}}$ was calculated based on impulse method determined with hydrochloric acid.

Table 7 shows the values of the $\mathrm{D} /(\mathrm{uL})$ and Péclet number at $50^{\circ} \mathrm{C}$ at different flow rates using impulse method with $\mathrm{HCl}$.

\section{Here Table 7.}

Table 7 confirms that axial dispersion in reactor 3 should be taken into account. For this reason, two different models were developed one by taking into account the axial dispersion effect and the other one based on the plug flow concept exclusively. 


\subsection{Estimation of the pressure drop}

The pressure drop for a fluid flowing through a column packed with solid particles is commonly evaluated by means of Ergun equation:

$$
\frac{\Delta \mathrm{P}}{\Delta \mathrm{L}}=\mathrm{A} \frac{\varepsilon_{\mathrm{RP}}^{2}}{\left(1-\varepsilon_{\mathrm{RP}}\right)^{3}} \frac{\mu_{\mathrm{f}}}{\left(\overline{\mathrm{d}}_{\mathrm{p}}\right)^{2}} \mathrm{u}_{\mathrm{f}}+\mathrm{B} \frac{\varepsilon_{\mathrm{RP}}}{\left(1-\varepsilon_{\mathrm{RP}}\right)^{3}} \frac{\rho_{\mathrm{f}}}{\overline{\mathrm{d}}_{\mathrm{P}}} \mathrm{u}_{\mathrm{f}}^{2}
$$

where,

$\varepsilon_{\mathrm{RP}}$ : fraction of solid in the reactor,

$1-\varepsilon_{\mathrm{RP}}$ void fraction in reactor,

$\bar{d}_{P}=\frac{6 \varepsilon_{R P}}{A_{s}}$, mean diameter particle and $A_{s}$ is external surface area of particle by volume of reactor, $\mathrm{m}^{2} / \mathrm{m}^{3}, \mu_{\mathrm{f}}$ : fluid viscosity, $\mathrm{Ns} / \mathrm{m}^{2}, \rho_{\mathrm{f}}$ : fluid density, $\mathrm{kg} / \mathrm{m}^{3}$ and $\mathrm{u}_{\mathrm{f}}$ : superficial velocity, $\mathrm{m} / \mathrm{s}$.

Water is the solvent in the system (around 50-55 wt. \%), for that reason water viscosity and density were used in Eq. (9). The external surface area of the particle was calculated based on the data from Table 3 and the nominal diameter of the wet Amberlite IR-120 were used $(0.5 \mathrm{~mm})$. Table 8 shows the fraction of solid in the reactor, parameter $A_{S}$, mean diameter of particle for each reactor.

\section{Here Table 8.}


According to Trambouze and Euzen (2002), in case of liquid phase system, the parameters A and B could change according to the nature of the liquid. According to Villermaux (1993), if $\frac{\operatorname{Re}_{P}}{\varepsilon_{R P}}<500$, then $A$ and $B$ are equal to 150 and 1.75, respectively. The Reynolds number for the particle is defined as:

$\operatorname{Re}_{\mathrm{p}}=\frac{\overline{\mathrm{d}}_{\mathrm{p}} \mathrm{u}_{\mathrm{f}} \rho_{\mathrm{f}}}{\mu_{\mathrm{f}}}$

The value of $\mathrm{Re}_{\mathrm{p}}$ varies between 0.06 and 0.8 for the different reactors; thus, the parameter $A$ and $B$ can be fixed to be equal to 150 and 1.75 , respectively.

By using Eq. (9), it was observed that the pressure drop is negligible, e.g., lower than $10^{-5} \mathrm{mBar} / \mathrm{m}$ in the superficial velocity range 9 (from $4.10^{-5}$ to $4.10^{-5} \mathrm{~m} / \mathrm{s}$ ) applied during the experiments. 


\subsection{Mass transfer effects}

Several methods exist in the literature to estimate the mass transfer coefficient $k_{D}$ in case of external mass transfer. The mass flux $N_{D}$ between the bulk phase and the surface of the catalyst is expressed as

$$
\mathrm{N}_{\mathrm{D}}=\mathrm{k}_{\mathrm{D}}\left(\mathrm{C}_{\mathrm{b}}-\mathrm{C}_{\mathrm{s}}\right)
$$

where $k_{D}$ is the mass transfer coefficient, $C_{b}$ and $C_{s}$ are the concentrations in the bulk and at the outer surface of the catalyst, respectively.

The coefficient $k_{D}\left(m \cdot s^{-1}\right)$ (Villermaux, 1993) can be estimated by calculating the Sherwood number (Sh) defined as

$\mathrm{Sh}=\frac{\mathrm{k}_{\mathrm{D}} \overline{\mathrm{d}}_{\mathrm{p}}}{D}=2+1.8 \operatorname{Re}_{\mathrm{p}}^{1 / 2} \mathrm{Sc}^{1 / 3}$

where $\mathrm{Sc}$ is the Schmidt number defined as

$$
\mathrm{Sc}=\frac{\mu_{\mathrm{f}}}{\rho_{\mathrm{f}} D}
$$

and $D$ is the molecular diffusion coefficient, estimated by using the Wilke-Chang equation (Salmi et al., 2010). The molar volumes of the dissolved components and the liquid viscosity are included in the Wilke-Chang equation. The molar volumes were calculated from the atomic increments of Le Bas. At $30^{\circ} \mathrm{C}$, the molecular diffusion coefficients of the different compounds present in the mixture are quite close $\left(1.29-3.3210^{-9} \mathrm{~m}^{2} . \mathrm{s}^{-1}\right)$.

Villermaux (1993) has defined the coefficient $f_{e}$ to determine the influence of the external mass transfer:

$$
\mathrm{f}_{\mathrm{e}}=\frac{\overline{\mathrm{r} L}}{\mathrm{k}_{\mathrm{D}} \mathrm{C}_{\mathrm{b}}}=\frac{\mathrm{C}_{\mathrm{b}}-\mathrm{C}_{\mathrm{S}}}{\mathrm{C}_{\mathrm{b}}}
$$

where $\overline{\mathrm{r}}$ is the initial observed reaction rate $\left(\mathrm{mol} \cdot \mathrm{m}^{-3} \cdot \mathrm{s}^{-1}\right)$, and $\mathrm{L}$ is defined as the ratio $V_{P} / A_{P}$. If $\mathrm{f}_{e}$ is less than $5 \%$, then the external mass transfer is negligible. 
Another way to estimate the mass transfer coefficient $k_{D}$ is to use the correlation proposed by Satterfield-Chilton-Colburn:

$$
\mathrm{j}_{\mathrm{D}}=\frac{\mathrm{k}_{\mathrm{D}} \mathrm{Sc}^{2 / 3}}{\mathrm{u}_{\mathrm{f}}}
$$

In case of a liquid-phase reaction and if $0.006<\mathrm{Re}_{\mathrm{p}}<55$ (Villermaux, 1993), the parameter $j_{D}$ is defined as:

$$
\mathrm{j}_{\mathrm{D}}=\frac{1.09}{\left(1-\varepsilon_{\mathrm{P}}\right) \operatorname{Re}_{\mathrm{P}}^{0.67}}
$$

The viscosity and density of water was used in the calculation. For the sake of simplicity, Table 9 summarizes the values of the different numbers used for

estimating the mass transfer coefficient $k_{D}$ and the value of $f_{e}$ in case of reactor 1 for the perhydrolysis of propionic acid. The molecular diffusion of propionic acid was used to calculate $\mathrm{k}_{\mathrm{D}}$ from Eq.(12).

\section{Here Table 9.}

Table 9 shows that the parameter $f_{e}$ is lower than $5 \%$, which proves the absence of external mass transfer. Furthermore, both values of $f_{e}$, i.e., calculated from $S h$ or $\mathrm{j}_{\mathrm{D}}$, are similar, confirming the previous conclusion. By using this methodology for the different reactors, no external mass transfer limitation was noticed for the synthesis of PAA or PPA. 
To estimate the importance of internal mass transfer, Villermaux (1993) has introduced the parameter $\varphi_{\mathrm{S}}^{\prime}$ defined as,

$\varphi_{\mathrm{S}}^{\prime}=\frac{\overrightarrow{\mathrm{r}} \mathrm{L}^{2}}{\mathrm{D}_{\mathrm{e}} \mathrm{C}_{\mathrm{S}}}$

where $L=V_{p} / A_{p}$,

If $\varphi_{\mathrm{S}}^{\prime}$ is lower than 0.1 , internal mass transfer is negligible. In our case, $\mathrm{C}_{\mathrm{S}}=\mathrm{C}_{\mathrm{b}}$ because there is no external mass transfer limitation. Indeed, when $\varphi_{\mathrm{S}}^{\prime}$ is equal to 0.1 , then deviation caused by internal diffusion limitation is about $6 \%$ for a firstorder reaction. The effective diffusion coefficient $\mathrm{D}_{\mathrm{e}}$ is defined as, $\mathrm{D}_{\mathrm{e}}=\frac{\varepsilon_{\mathrm{P}}}{\tau} D$, where $\varepsilon_{P}$ is the porosity and $\tau$ is the tortuosity factor of the material. In case of Amberlite IR-120, the porosity is equal to 0.5 and the tortuosity factor was estimated to be 2.2 (Leveneur et al., 2009d). The molecular diffusion coefficient $D$ of propionic acid was estimated by using the Wilke-Chang equation.

The value of $\varphi_{\mathrm{S}}^{\prime}$ for the synthesis of peroxypropionic acid performed with reactor 1 was estimated to 0.02 at $30^{\circ} \mathrm{C}$, showing the absence of internal mass transfer limitation. This tendency was observed for the different experiments carried out during this study, i.e., the absence of internal mass transfer. 


\subsection{Mass balance of the system}

The pressure drop, evaluated by Ergun equation; external and internal mass transfer phenomena, evaluated by several correlations (Trambouze and Euzen, 2002), were found to be negligible. Thus, based on the evidence provided in previous section the pseudo-homogeneous model was applied to the fixed-bed reactor. The mass balance of a component (i) is written as follows:

$$
\dot{\mathrm{n}}_{\mathrm{i}, \text { in }}+\left(-\mathrm{D}_{\mathrm{a}} \frac{\partial \mathrm{C}_{\mathrm{i}}}{\partial \mathrm{l}} \mathrm{A}_{1}\right)_{\text {in }}+\mathrm{r}_{\mathrm{i}, \text { tot }} \Delta \mathrm{V}_{\mathrm{L}}=\dot{\mathrm{n}}_{\mathrm{i}, \text { out }}+\left(-\mathrm{D}_{\mathrm{a}} \frac{\partial \mathrm{C}_{\mathrm{i}}}{\partial \mathrm{l}} \mathrm{A}_{1}\right)_{\text {out }}+\frac{\partial \mathrm{n}_{\mathrm{i}}}{\partial \mathrm{t}}
$$

where the area element is defined by

$$
A_{l}=2 \pi r \Delta r
$$

The axial dispersion coefficient is defined by $D_{a}=\varepsilon D$, where $\varepsilon$ is the liquid hold-up defined by $\varepsilon=V_{L} / V$, $V$ being the total volume of the reactor. The differences can be written by the operator $\Delta$ :

$$
\Delta\left(\mathrm{D}_{\mathrm{a}} \frac{\partial \mathrm{C}_{\mathrm{i}}}{\partial \mathrm{l}} \mathrm{A}_{1}\right)+\mathrm{r}_{\mathrm{i}, \mathrm{tot}} \Delta \mathrm{V}_{\mathrm{L}}=\Delta \dot{\mathrm{n}}_{\mathrm{i}}+\frac{\partial \mathrm{n}_{\mathrm{i}}}{\partial \mathrm{t}}
$$

The volume element is $\Delta V=A_{l} \Delta$ l and the amount of substance can be written as $n_{i}$

$=\mathrm{c}_{\mathrm{i}} \Delta \mathrm{V}_{\mathrm{L}}=\mathrm{c}_{\mathrm{i}} \varepsilon \Delta \mathrm{V}$. By dividing Eq.(19) by $2 \pi r \Delta r \Delta l$ and assuming $\mathrm{D}_{\mathrm{a}}$ constant, Eq. (19) becomes

$\mathrm{D}_{\mathrm{a}} \frac{\Delta\left(\frac{\partial \mathrm{C}_{\mathrm{i}}}{\partial \mathrm{l}}\right)}{\Delta \mathrm{l}}+\mathrm{r}_{\mathrm{i}, \text { tot }} \frac{\varepsilon \Delta \mathrm{V}}{2 \pi \mathrm{r} \Delta \mathrm{r} \Delta \mathrm{l}}=\frac{\Delta \dot{\mathrm{n}}_{\mathrm{i}}}{2 \pi \mathrm{r} \Delta \mathrm{r} \Delta \mathrm{l}}+\frac{\partial \mathrm{n}_{\mathrm{i}}}{2 \pi \mathrm{r} \Delta \mathrm{r} \Delta \mathrm{l} \partial \mathrm{t}}$

The relationship between superficial velocity $\mathrm{w}$ and length of reactor is $w=\frac{l}{\bar{t}}$.

Thus, Eq.(20) becomes: 
$\frac{\mathrm{D}_{\mathrm{a}}}{w^{2}} \frac{\Delta\left(\frac{\partial \mathrm{C}_{\mathrm{i}}}{\partial \overline{\mathrm{t}}}\right)}{\Delta \overline{\mathrm{t}}}+\mathrm{r}_{\mathrm{i}, \mathrm{tot}} \varepsilon=\frac{\Delta \dot{\mathrm{n}}_{\mathrm{i}}}{2 \pi \mathrm{r} \Delta \mathrm{r} \Delta \mathrm{l}}+\frac{\partial \mathrm{n}_{\mathrm{i}}}{2 \pi \mathrm{r} \Delta \mathrm{r} \Delta \mathrm{l} \partial \mathrm{t}}$

The following expression for the molar flow is valid:

$$
\Delta \dot{\mathrm{n}}_{\mathrm{i}}=\Delta\left(\mathrm{c}_{\mathrm{i}} \mathrm{w}\right) 2 \pi \mathrm{r} \Delta \mathrm{r}
$$

Then,

$$
\frac{\Delta \dot{\mathrm{n}}_{\mathrm{i}}}{2 \pi \mathrm{r} \Delta \mathrm{r} \Delta \mathrm{l}}=\frac{\Delta\left(\mathrm{c}_{\mathrm{i}} w\right)}{\Delta \mathrm{l}}=\frac{\Delta\left(\mathrm{c}_{\mathrm{i}}\right)}{\Delta \overline{\mathrm{t}}}
$$

Letting $\Delta \overline{\mathrm{t}} \rightarrow 0$, the mass balance becomes:

$$
\frac{\mathrm{D}_{\mathrm{a}}}{w^{2}} \frac{\partial^{2} \mathrm{c}_{\mathrm{i}}}{\partial \overline{\mathrm{t}}^{2}}+\mathrm{r}_{\mathrm{i}, \mathrm{tot}} \varepsilon=\frac{\partial \mathrm{c}_{\mathrm{i}}}{\partial \overline{\mathrm{t}}}+\varepsilon \frac{\partial \mathrm{c}_{\mathrm{i}}}{\partial \mathrm{t}}
$$

At steady state regime, there is no accumulation, $\frac{\partial \mathrm{c}_{i}}{\partial \mathrm{t}}=0$ and the equation is simplified to

$\frac{\mathrm{D}_{\mathrm{a}}}{w^{2}} \frac{\partial^{2} \mathrm{c}_{\mathrm{i}}}{\partial \overline{\mathrm{t}}^{2}}+\mathrm{r}_{\mathrm{i}, \mathrm{tot}} \varepsilon=\frac{\partial \mathrm{c}_{\mathrm{i}}}{\partial \overline{\mathrm{t}}}$

The Danckwerts boundary conditions were applied for differential equation,

at the reactor inlet $c_{o i}=c_{i}-\frac{D_{a}}{w^{2}} \frac{d_{i}}{d \bar{t}}$ at $\bar{t}=0$

at the reactor outlet $\frac{\mathrm{dc}_{\mathrm{i}}}{\mathrm{d} \overline{\mathrm{t}}}=0$ at $\overline{\mathrm{t}}$

In case of absence of axial dispersion and at steady-state, Eq.(19) leads to :

$$
\mathrm{r}_{\mathrm{i}, \text { tot }} \Delta \mathrm{V}_{\mathrm{L}}=\Delta \dot{\mathrm{n}}_{\mathrm{i}}
$$

The volume element is $\Delta \mathrm{V}=\mathrm{A}_{\mathrm{l}} \Delta \mathrm{l}$, superficial velocity is $w=\frac{l}{\bar{t}}$ and by using Eq.(22), we get, 


$$
\varepsilon r_{i, t o t}=\frac{d_{i}}{d \bar{t}}
$$

i.e., the plug flow model. 


\subsection{Kinetic expression for perhydrolysis}

In a previous paper of our group (Leveneur et al., 2009d), the kinetics of peroxycarboxylic acid synthesis was described in detail. Perhydrolysis is a reversible reaction governed by the value of the equilibrium constant $\mathrm{K}^{\mathrm{c}}$.

Based on the experimental data obtained from a batch reactor, an Eley-Rideal mechanism was assumed to operate, but the autoprotolysis of carboxylic acid itself gives some contribution to the overall reaction rate.

\section{Here Fig. 11.}

From Fig. 11, it should be noticed that the mechanism can be divided into two parts: the homogeneous part $r_{\text {hom }}$ due to the protolysis of carboxylic acids producing hydroxonium ions, which act catalytically; and the heterogeneous part $r_{\text {het }}$ due to the sulphonic groups on the resins. The peroxycarboxylic acid is a much weaker acid than the corresponding carboxylic acid. Therefore, the acid-catalytic effect of the peroxycarboxylic acid is not included in the scheme. The details of the calculation of the homogeneously catalyzed part are given in the previous article (Leveneur et al., 2008). The total rate $r_{\text {tot }}$ of the reaction is the sum of the rates of the reactions 2 and 6, in Fig. 11 .

$$
\begin{aligned}
\mathrm{r}_{\mathrm{tot}} & =\mathrm{r}_{\mathrm{hom}}+\mathrm{r}_{\mathrm{het}} \\
& =\left[\frac{\mathrm{k}_{\mathrm{hom}} * \sqrt{\mathrm{K}_{\mathrm{CA}, \mathrm{diss}} *[\mathrm{CA}] *[\mathrm{~W}]}}{[\mathrm{W}]}+\frac{\mathrm{k}_{\mathrm{het}} * \rho_{\mathrm{LB}} * \mathrm{Cap} .(4.7 \mathrm{meq} / \mathrm{g})}{1+\mathrm{K}_{\mathrm{ads}, \mathrm{CA}, \mathrm{PCA}}^{\mathrm{C}} *([\mathrm{CA}]+[\mathrm{PCA}])+\mathrm{K}_{\mathrm{ads}, \mathrm{W}}^{\mathrm{C}} *[\mathrm{~W}]}\right] * \\
& {\left[[\mathrm{CA}] *[\mathrm{HP}]-\frac{1}{\mathrm{~K}^{\mathrm{C}}} *[\mathrm{PCA}] *[\mathrm{~W}]\right] }
\end{aligned}
$$


where $\rho_{\mathrm{LB}}$ represents the amount of dried catalyst $(\mathrm{kg})$ per volume of void $\left(\mathrm{V}_{\mathrm{L}}\right)$ in each section of the reactor.

The concentration-based equilibrium constant $\mathrm{K}^{\mathrm{C}}$ is defined as: $\mathrm{K}^{\mathrm{c}}=\frac{\mathrm{K}^{\mathrm{T}}}{\mathrm{K}^{\gamma}}$, where $\mathrm{K}^{\mathrm{V}}$ represents the equilibrium ratio calculated based on the activity coefficients and $\mathrm{K}^{\top}$ is the thermodynamic equilibrium constant. For the sake of simplicity, $\mathrm{K}^{\mathrm{V}}$ was assumed to be constant in the temperature range $30-60^{\circ} \mathrm{C}$, and, the constant $\mathrm{K}^{\mathrm{C}}$ was calculated as: $\mathrm{K}^{\mathrm{c}}=\frac{\mathrm{K}^{\mathrm{T}}}{\mathrm{K}^{\gamma}}$, where $\mathrm{K}^{\gamma}$ was found to be equal to 0.8 (Leveneur et al., 2009d), and $\mathrm{K}^{\top}$ was determined from $\ln \frac{\mathrm{K}^{\mathrm{T}}}{\mathrm{K}_{\mathrm{ref}}^{\mathrm{T}}}=\frac{-\Delta \mathrm{H}_{\mathrm{r}}^{\mathrm{o}}}{\mathrm{R}}\left(\frac{1}{\mathrm{~T}}-\frac{1}{\mathrm{~T}_{\mathrm{ref}}}\right)$. The parameters $\Delta \mathrm{H}_{\mathrm{r}}^{\mathrm{o}}$ and $\mathrm{K}_{\mathrm{ref}}^{\mathrm{T}}$ were estimated from a previous model for peroxyacetic and peroxypropionic acid synthesis (Leveneur et al., 2009d). The value for the adsorption coefficient of water $\mathrm{K}_{\mathrm{ads}, \mathrm{W}}^{\mathrm{C}}$ (equal to 0.72 at $45^{\circ} \mathrm{C}$ ) was calculated based on the equation developed by Altiokka (2007), and $\mathrm{K}_{\mathrm{CA} \text {,diss }}$ (equal to $2.810^{-7}$ for acetic acid and $2.210^{-7}$ for propionic acid at $45^{\circ} \mathrm{C}$ ) was estimated from Sue et al. (2004). The parameter $\mathrm{K}_{\mathrm{ads}, \mathrm{CA}, \mathrm{PCA}}^{\mathrm{C}}$ was estimated by the model (Leveneur et al., 2009d).

Eq. (25) was used only in the case of reactor 3 for the synthesis of peroxyacetic acid, where the presence of axial dispersion was confirmed by the RTD measurement. 


\subsection{Reactor modelling results}

In the sake of simplicity, the liquid hold-up was assumed to be constant in the different part of the reactors. By making this assumption, one can calculate the $\overline{\mathrm{t}}$ of each section of the reactor, and define a global axial dispersion parameter.

The parameter estimation was carried out by a special software Modest for simulation and parameter estimation (Haario, 2001). The objective function $\theta$ was minimized by using Simplex and Levenberg-Marquardt algorithms. This objective function was defined as follows $\theta=\Sigma\left(c_{i}-\hat{c}_{i}\right)^{2}$ where $c_{i}$ is the experimental concentration and $\hat{c}_{i}$ is the estimated concentration. The concentrations of CA, PCA and $\mathrm{H}_{2} \mathrm{O}_{2}$ were included in the objective function with equal weights.

In this model, two parameters were estimated by regression analysis: $\mathrm{k}_{\mathrm{ave}}$ and Ea with the reference temperature fixed at $45^{\circ} \mathrm{C}$. The temperature dependence of the rate constant was described by a modified Arrhenius equation:

$\mathrm{k}=\mathrm{k}_{\mathrm{ave}} \exp \left(\frac{-\mathrm{Ea}}{\mathrm{R}}\left(\frac{1}{\mathrm{~T}}-\frac{1}{\mathrm{~T}_{\mathrm{ave}}}\right)\right)$

where $\mathrm{k}_{\mathrm{ave}}=\mathrm{Ae} \mathrm{e}^{-\left(\frac{\mathrm{Ea}}{\mathrm{RT}_{\mathrm{ave}}}\right)}, \mathrm{T}_{\text {ave }}$ is the average temperature of the experiments. The goal of this modification is to suppress the correlation between the frequency factor and the activation energy during the parameter estimation.

The coefficient of explanation $\mathrm{R}^{2}$ of the kinetic models is defined as follows:

$$
\mathrm{R}^{2}=1-\frac{\sum\left(\mathrm{c}_{\mathrm{i}}-\hat{\mathrm{c}_{\mathrm{i}}}\right)^{2}}{\sum\left(\mathrm{c}_{\mathrm{i}}-\overline{\mathrm{c}_{\mathrm{i}}}\right)^{2}}
$$


where $c_{i}$ is the experimental concentration, $\hat{c}$ is the estimated concentration and $\bar{c}$ is the mean value of the observed concentrations.

3.6.1 Absence of axial dispersion - plug flow model

The generation rates of the chemical compounds are combined to the mass balances valid for the continuous reactor (Eq. 27),

$$
\begin{aligned}
& \frac{\mathrm{d}[\mathrm{PA}]}{\mathrm{d} \overline{\mathrm{t}}}=-\varepsilon \mathrm{r}_{\mathrm{i}, \text { tot }} \\
& \frac{\mathrm{d}[\mathrm{PPA}]}{\mathrm{d} \overline{\mathrm{t}}}=+\varepsilon \mathrm{r}_{\mathrm{i}, \text { tot }} \\
& \frac{\mathrm{d}\left[\mathrm{H}_{2} \mathrm{O}_{2}\right]}{\mathrm{d} \overline{\mathrm{t}}}=-\varepsilon \mathrm{r}_{\mathrm{i}, \text { tot }} \\
& \frac{\mathrm{d}\left[\mathrm{H}_{2} \mathrm{O}\right]}{\mathrm{d} \overline{\mathrm{t}}}=+\varepsilon \mathrm{r}_{\mathrm{i}, \text { tot }}
\end{aligned}
$$

This ordinary differential equation system was solved with backward difference method implemented in the software Odessa, which is a part of the Modest package. Fig. 12 shows the modelling results obtained in case of negligible axial dispersions.

\section{Here Fig. 12.}

One should remember that the reactor was divided into different sections, which were alternatively fed with inert materials and catalysts. By assuming that the liquid hold-up was the same along the reactor, it was possible to determine the mean residence time $\bar{t}$ at the different section of the continuous reactor. 
The explanation coefficient for this model is $99.40 \%$. Table 10 gives the values of the estimated parameters.

Here Table 10.

\section{Here Fig. 13}

Fig. 13 represents the contour plot of Ea versus $k_{\text {ave }}$ demonstrating a wellpronounced minimum, and the parameters are rather well defined. The average rate constant and activation energy for the synthesis of peroxypropionic acid in batch reactor were estimated to be equal to $\mathrm{k}_{\text {ave }}=0.9110^{-3} \mathrm{I} \cdot \mathrm{mol}^{-1} \cdot \mathrm{s}^{-1}$ and Ea $=$ $51.4 \mathrm{~kJ} . \mathrm{mol}^{-1}$, respectively. One can notice that the kinetic parameters are in fairly good agreement. 


\subsubsection{Modelling in the presence of axial dispersion}

According to the RTD measurement, the presence of axial dispersion was noticed in the experiments carried out with reactor 3 . By combining the generation rates with the mass balance Eq. (25), the following set of differential equations is obtained

$$
\begin{aligned}
& \frac{\mathrm{D}_{\mathrm{a}}}{w^{2}} \frac{\partial^{2}[\mathrm{AA}]}{\partial \overline{\mathrm{t}}^{2}}-\mathrm{r}_{\mathrm{tot}} \varepsilon=\frac{\partial[\mathrm{AA}]}{\partial \overline{\mathrm{t}}} \\
& \frac{\mathrm{D}_{\mathrm{a}}}{w^{2}} \frac{\partial^{2}[\mathrm{PAA}]}{\partial \overline{\mathrm{t}}^{2}}+\mathrm{r}_{\mathrm{tot}} \varepsilon=\frac{\partial[\mathrm{PAA}]}{\partial \overline{\mathrm{t}}} \\
& \frac{\mathrm{D}_{\mathrm{a}}}{w^{2}} \frac{\partial^{2}\left[\mathrm{H}_{2} \mathrm{O}_{2}\right]}{\partial \overline{\mathrm{t}}^{2}}-\mathrm{r}_{\mathrm{tot}} \varepsilon=\frac{\partial\left[\mathrm{H}_{2} \mathrm{O}_{2}\right]}{\partial \overline{\mathrm{t}}} \\
& \frac{\mathrm{D}_{\mathrm{a}}}{w^{2}} \frac{\partial^{2}\left[\mathrm{H}_{2} \mathrm{O}\right]}{\partial \overline{\mathrm{t}}^{2}}+\mathrm{r}_{\mathrm{tot}} \varepsilon=\frac{\partial\left[\mathrm{H}_{2} \mathrm{O}\right]}{\partial \overline{\mathrm{t}}}
\end{aligned}
$$

These differential equations were transformed to ordinary differential equation using central finite difference method. The axial dispersion coefficient $D_{a}$ and the kinetic parameters such as rate constant $\mathrm{k}_{\mathrm{ave}}$ and $\mathrm{Ea}$ were estimated by regression. Fig. 14 shows the modelling results obtained in presence of axial dispersion. 
Here Fig. 14.

The explanation coefficient for this model became $99.20 \%$, and the Table 11 gives the value of the estimated parameters and the standard error values.

\section{Here Table 11.}

For this modelling, the estimated parameters were further checked by parameter sensitivity analysis plots using the Markov Chain Monte Carlo (MCMC) method (Fig. 15). Fig. 15 indicates that the parameters are really well identified.

Here Fig. 15. 


\section{CONCLUSIONS}

The goal of this paper was to demonstrate the feasibility and the possibility to scale-up the production of peroxycarboxylic acid (PAA and PPA) from carboxylic acid and hydrogen peroxide in a continuously operating fixed-bed reactor, in the presence of a heterogeneous catalyst. The experimental setup allows to take samples at different locations in the reactor. Thus, the experimental concentration profile can be verified with modelling.

Residence time distribution measurements were carried out by step and pulse methods and with different tracer molecules. The experiments carried out by pulse method using $\mathrm{HCl}$ as a tracer gave a better description of the flow pattern. It was observed that neither the reactor temperature nor the catalyst distribution inside the reactor has an influence on the flow pattern. The increase of the average diameter of the particles led to an increase of the mean residence time, since the void fraction of the bed increased. In case of experiments carried out with a low catalyst loading (i.e., reactor 3), axial dispersion phenomenon cannot be neglected, but has to be taken into account in the modelling.

By using the Ergun equation, it was found that the pressure drop is negligible in this study. Several correlations confirmed the fact that external and internal mass transfer are absent under the experimental conditions used. Based on these conclusions, a steady-state pseudo-homogeneous model with and without axial dispersion was developed to estimate the kinetic parameters at the temperature range of $30-50^{\circ} \mathrm{C}$. The validity of this model is correct for a water concentration 
range of $27.80-48.7 \mathrm{M}$, a carboxylic acid concentration range of $5.10-5.90 \mathrm{M}$, a hydrogen peroxide concentration of $6.10-7.00 \mathrm{M}$, a flow rate of $0.6-3.6 \mathrm{ml} \cdot \mathrm{min}^{-1}$ and different catalyst loadings were used, from 25.0 to $48.7 \mathrm{~g}$. The kinetic model developed is able to fairly describe the system in the presence and absence of axial dispersion. 


\section{AKNOWLEDGEMENTS}

The financial support from the Åbo Akademi Forskningsinstitut and the Finnish Graduate School in Chemical Engineering (GSCE) are gratefully acknowledged. This work is part of the activities at the Åbo Akademi Process Chemistry Centre (PCC) within the Finnish Centre of Excellence Programme (2006-2011) by the Academy of Finland. 


\section{NOTATION}
A
interfacial area $\left[\mathrm{m}^{2}\right]$
$\mathrm{A}_{\mathrm{s}}$
external surface area of the particle by volume, $\mathrm{m}^{2} / \mathrm{m}^{3}$
C
concentration $\left[\mathrm{mol} . \mathrm{I}^{-1}\right]$
D
axial dispersion coefficient $\left[\mathrm{m}^{2} \cdot \mathrm{s}^{-1}\right]$
$D$
molecular diffusion coefficient $\left[\mathrm{m}^{2} . \mathrm{s}^{-1}\right]$
De
effective diffusion coefficient $\left[\mathrm{m}^{2} \cdot \mathrm{s}^{-1}\right]$
Ea
activation energy [ $\left.\mathrm{J} \cdot \mathrm{mol}^{-1}\right]$
F
volumetric flow rate of the fluid [ml/min]
$f_{e}$
coefficient to evaluate the influence of external mass transfer
$\Delta \mathrm{H}_{\mathrm{r}}^{\circ}$
standard reaction enthalpy $\left[\mathrm{kJ} . \mathrm{mol}^{-1}\right]$
$\mathrm{j}_{\mathrm{D}}$

$$
\frac{\mathrm{k}_{\mathrm{D}} \mathrm{Sc}^{2 / 3}}{\mathrm{u}_{\mathrm{f}}}
$$
$\mathrm{K}^{\mathrm{c}}$
equilibrium constant, based on concentrations
$\mathbf{K}^{\top}$
thermodynamic equilibrium constant, based on activies
$\mathrm{K}^{\mathrm{N}}$
equilibrium constant, based on activity coefficients
$\mathrm{K}$
adsorption coefficient $\left[1 . \mathrm{mol}^{-1}\right]$
k
rate constant $\left[1 . \mathrm{mol}^{-1} \cdot \mathrm{s}^{-1}\right]$
$k_{D}$
mass transfer coefficient $[\mathrm{m} / \mathrm{s}]$
L
vessel length [m]
N
flux $\left[\mathrm{mol} \cdot \mathrm{m}^{-2} \cdot \mathrm{s}^{-1}\right]$ 


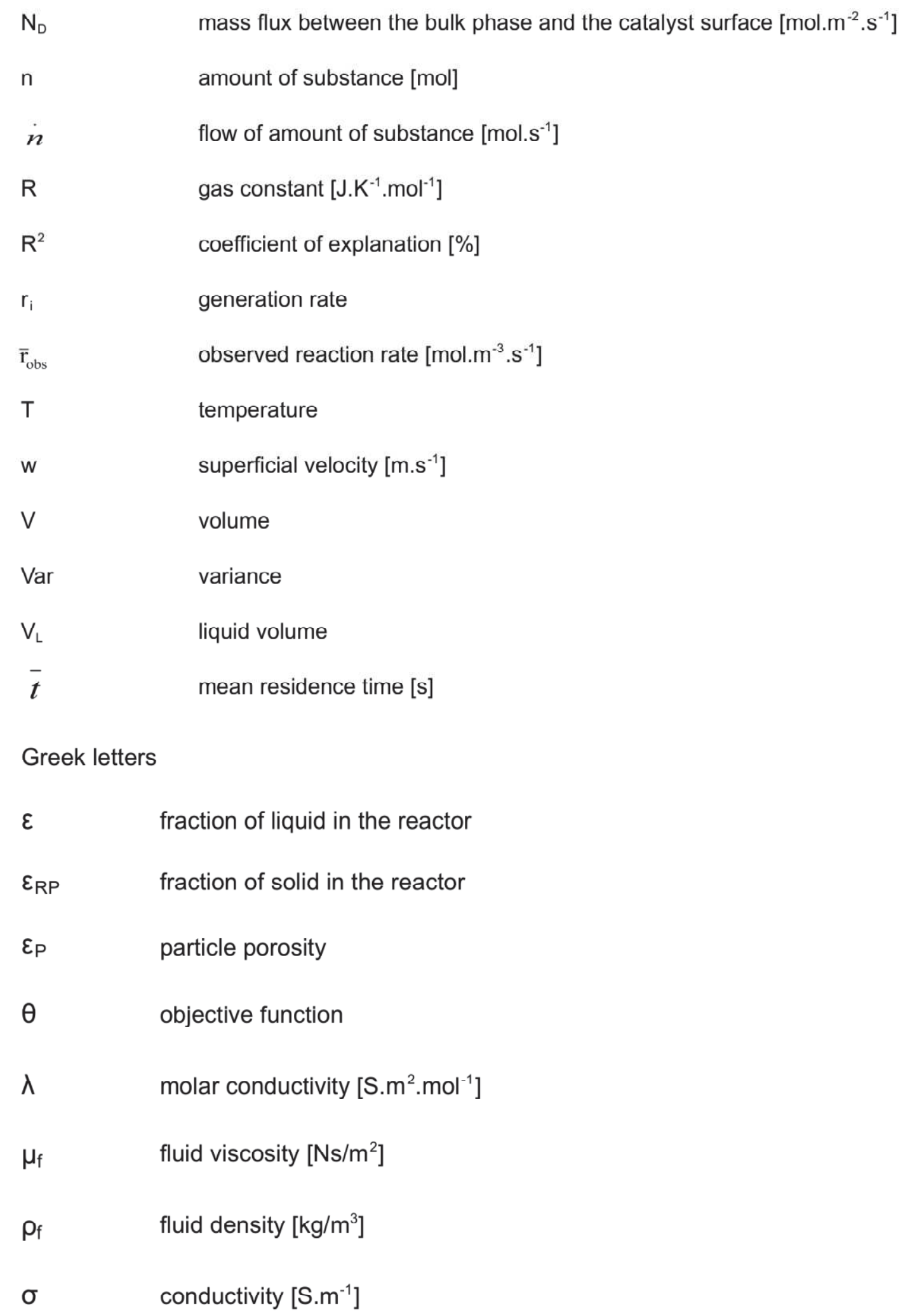




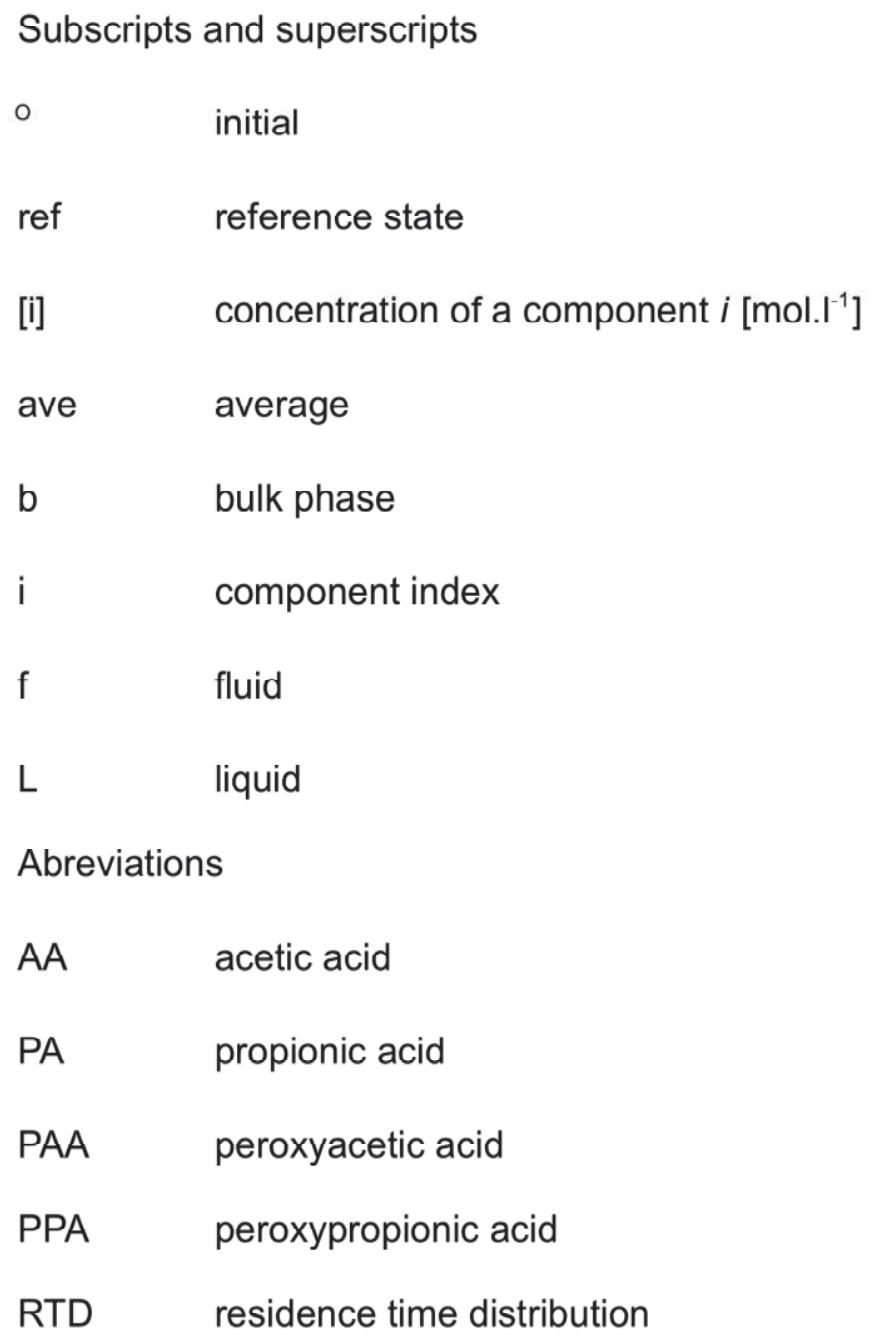




\section{REFERENCES}

Altiokka, M.R., 2007. Kinetics of hydrolysis of benzaldehyde dimethyl acetal over Amberlite IR-120. Ind. Eng. Res. 46, 1058-1062.

Cantieni, R., 1937. Photochemical peroxide formation. VII. Oxidation of acetic, propionic, butyric and isovaleric acids by means of molecular oxygen in ultraviolet light. Zeitschrift fuer Wissenschaftliche Photographie, Photophysik und Photochemie. 36, 90-95.

Chander, A., Kundu, A., Bej, S. K., Dalai, A. K., Vohra D. K., 2001. Hydrodynamic characteristics of cocurrent upflow and downflow of gas and liquid in a fixed bed reactor. Fuel, 80(8), 1043-1053.

Greenspan, F.P., Mackellar, D.G., 1948. Analysis of aliphatic per acids. Anal. Chem. 20, 1061-1063.

Haario, H., 2001. MODEST-User's Guide. Profmath Oy, Helsinki.

Hawkinson, A.T., Schitz, W.R., 1957. Improvements in or relating to the oxidation of aliphatic carboxylic acids to peracids. GB776758.

Leveneur, S., Salmi, T., Murzin, D. Yu., Estel, L., Wärnå, J., Musakka, N., 2008. Kinetic Study and Modeling of Peroxypropionic Acid Synthesis from Propionic Acid and Hydrogen Peroxide using Homogeneous Catalysts. Ind. Eng. Chem. Res., 47(3), 656-664.

Leveneur, S., Murzin, D. Yu., Salmi, T., 2009. Application of linear free-energy relationships to perhydrolysis of different carboxylic acids over homogeneous and heterogeneous catalysts. J. Mol. Catal. A Chem. 303, 148-155.

Leveneur, S., Murzin, D. Yu., Salmi, T., Mikkola, J.-P., Kumar, N., Eränen, K., Estel, L., 2009. Synthesis of peroxypropionic acid from propionic acid and hydrogen peroxide over heterogeneous catalysts. Chem. Eng. J. 147, 323-329. 
Leveneur, S., Wärnå, J., Salmi, T., Murzin, D. Yu., Estel, L., 2009. Interaction of intrinsic kinetics and internal mass transfer in porous ion-exchange catalysts: green synthesis of peroxycarboxylic acids. Chem. Eng. Sci. 64 (19), 4104-4114. Levenspiel, O., 1999. Chemical Reaction Engineering. 3rd ed., John Wiley \& Sons, Inc., New York.

Musante, R.L., Grau, R.J., Baltanas, M.A., 2000. Kinetic of liquid-phase reactions catalyzed by acidic resins: the formation of peracetic acid for vegetable oil epoxidation. Appl. Catal. A 197(1), 165-173.

Noyori, R., 2005. Pursuing practical elegance in chemical synthesis. Chem.Commun. 14, 1807-1811.

Phillips, B., Starcher, P. S., Ash, B.D., 1958. Preparation of aliphatic peroxyacids. J. Org. Chem. 23, 1823-1826.

Rüsch gen. Klaas, M., Steffens, K., Patett, N., 2002. Biocatalytic peroxy acid formation for disinfection. J. Mol. Catal. B-Enzym. 19-20, 499-505.

Saha, M.S, Nishiki, Y., Furuta, T., Denggerile, A., Ohsaka, T., 2003. A new method for the preparation of peroxyacetic acid using solid superacid catalysts. Tetrahedron Lett. 44(29), 5535-5537.

Salmi, T.O., Mikkola, J.-P., Wärnå, J.P., 2010. Chemical reaction engineering and reactor technology. 1st Ed. CRC Press.

Sue, K., Ouchi, F., Minami, K., Arai, K., 2004. Determination of carboxylic acid dissociation constants to $350^{\circ} \mathrm{C}$ at $23 \mathrm{MPa}$ by potentiometric $\mathrm{pH}$ measurements. $\mathrm{J}$. Chem. Eng. Data. 49 1359-1363.

Trambouze, P., Euzen, J.-P., 2002. Les Réacteurs Chimiques. Editions TECHNIP, Paris.

Villermaux, J., 1993. Génie de la Réaction Chimique. 2nd ed., Tec\&Doc Lavoisier. 


\section{FIGURES}

Scheme 1. Schematic view of the catalyst loadings in the fixed-bed reactor.

Fig. 1. Experimental scheme of the continuous fixed-bed reactor for continuous peroxycarboxylic acid production.

Fig.2. E-curves at $30^{\circ} \mathrm{C}$ by using $\mathrm{HCl}$ as a tracer.

Fig. 3. Flow rate versus the inverse of the mean residence time at $50^{\circ} \mathrm{C}$ for reactor 4.

Fig. 4. Flow rate versus the inverse of the mean residence time at $50^{\circ} \mathrm{C}$.

Fig. 5. Evolution of $\overline{\mathrm{t}}$ in different reactors.

Fig. 6. E-curves for reactor 3 at different flow rates.

Fig. 7. E-curves for reactor 4 at $50^{\circ} \mathrm{C}$ using a $1 \mathrm{M}$ of propionic acid solution.

Fig. 8. F-curve for reactor 4 at $50^{\circ} \mathrm{C}$ with an $\mathrm{HCl}$ solution at $0.003 \mathrm{M}$.

Fig. 9. Flow rate versus in the reactor 4 at $50^{\circ} \mathrm{C}$.

Fig. 10. Flow rate versus the reciprocal value of the mean residence time for reactor 4 at $50^{\circ} \mathrm{C}$.

Fig. 11. Simplified mechanism for peroxycarboxylic acid synthesis by Amberlite IR120 in aqueous medium.

Fig. 12. Fit of the plug flow model to the perhydrolysis experiments of propionic acid.

Fig. 13. Contour plot for the kinetic parameters.

Fig. 14. Fit of the axial dispersion model to the perhydrolysis of acetic acid carried out with reactor 3.

Fig. 15. Plots of the parameter sensitivity analysis (MCMC). 


\section{TABLES}

Table 1. Experimental matrix.

Table 2. Quartz and catalyst properties.

Table 3. Properties of Amberlite IR-120.

Table 4. Evolution of the dispersion parameter D/uL and Pé.

Table 5. Parameter D/(uL) and Péclet number for reactor 3.

Table 6. Dispersion parameters for impulse experiments with propionic acid.

Table 7. Dispersion parameters of the different reactors at $50^{\circ} \mathrm{C}$.

Table 8. Geometric parameters of the reactors.

Table 9. External mass transfer parameters for reactor 1 for propionic acid.

Table 10. Estimated parameters and values of standard errors at $45^{\circ} \mathrm{C}$ with $\mathrm{R}^{2}$ : $99.40 \%$.

Table 11. Estimated Parameters and Values of Standard Errors at $45^{\circ} \mathrm{C}$ with $\mathrm{R}^{2}$ : $99.20 \%$. 
Table 1. Experimental matrix.

\begin{tabular}{|c|c|}
\hline Loading of quartz balls $[\mathrm{g}]$ & $57.6-99.5$ \\
\hline Loading of wet Amberlite IR-120 [g] & $25.0-48.7$ \\
\hline Flow rate $\left[\mathrm{ml} . \mathrm{min}^{-1}\right]$ & $0.6-3.6$ \\
\hline Temperature $\left[{ }^{\circ} \mathrm{C}\right]$ & $30-50$ \\
\hline$[\mathrm{CA}]_{\circ}\left[\mathrm{mol} . \mathrm{I}^{-1}\right]$ & $5.10-5.90$ \\
\hline$\left[\mathrm{H}_{2} \mathrm{O}_{2}\right]_{\circ}\left[\mathrm{mol} . .^{-1}\right]$ & $6.10-7.00$ \\
\hline$\left[\mathrm{H}_{2} \mathrm{O}\right]_{\circ}\left[\mathrm{mol}^{-1}{ }^{-1}\right]$ & $24.80-31.40$ \\
\hline
\end{tabular}


Click here to download Figure: Table 2.doc

Table 2. Quartz and catalyst properties.

\begin{tabular}{|l|c|l|c|}
\hline \multicolumn{2}{|c|}{ Quartz } & \multicolumn{2}{c|}{ Amberlite IR-120 } \\
\hline Diameter $[\mathrm{mm}]$ & 3 & Diameter $[\mathrm{mm}]$ & $0.15-0.90$ \\
\hline Density $\left[\mathrm{kg} \cdot \mathrm{m}^{-3}\right]$ & 2687 & True density $\left[\mathrm{kg} \cdot \mathrm{m}^{-3}\right]$ & 1260 \\
\hline & Porosity & 0.5 \\
\hline
\end{tabular}


Click here to download Figure: Table 3.doc

Table 3. Properties of Amberlite IR-120.

\begin{tabular}{|c|c|}
\hline Polymer type & Gel \\
\hline Cross linking, \% & 8 \\
\hline Moisture content, \% mass & 45 \\
\hline Capacity by dry weight, meq/g & 4.7 \\
\hline Particle size range, mm & 0.9 \\
\hline
\end{tabular}


Table 4. Evolution of the dispersion parameter D/uL and Pé.

\begin{tabular}{|c|c|c|c|c|}
\hline & Temperature $\left[{ }^{\circ} \mathrm{C}\right]$ & $\bar{t}$ [min] & $\frac{\mathrm{D}}{\mathrm{uL}}$ & Pé \\
\hline \multirow{5}{*}{$\begin{array}{l}\bar{\alpha} \\
\frac{\sigma}{0} \\
\frac{\omega}{\alpha} \\
\frac{w}{\alpha}\end{array}$} & 50 & 50 & 0.006 & 168 \\
\hline & 50 & 28 & 0.007 & 138 \\
\hline & 50 & 13 & 0.008 & 119 \\
\hline & 50 & 10 & 0.011 & 91 \\
\hline & 50 & 7 & 0.011 & 91 \\
\hline \multirow{6}{*}{$\begin{array}{l}+ \\
\frac{\alpha}{0} \\
\frac{0}{0} \\
\underset{\alpha}{\alpha} \\
\frac{\alpha}{\alpha}\end{array}$} & 50 & 34 & 0.007 & 140 \\
\hline & 50 & 17 & 0.011 & 90 \\
\hline & 50 & 13 & 0.007 & 141 \\
\hline & 50 & 10 & 0.007 & 138 \\
\hline & 50 & 9 & 0.009 & 117 \\
\hline & 50 & 7 & 0.007 & 137 \\
\hline
\end{tabular}


Click here to download Figure: Table 5.doc

Table 5. Parameter D/(uL) and Péclet number for reactor 3.

\begin{tabular}{|c|c|c|c|c|}
\hline & Temperature $\left[{ }^{\circ} \mathrm{C}\right]$ & $\overline{\mathrm{t}}[\mathrm{min}]$ & $\frac{\mathrm{D}}{\mathrm{uL}}$ & Pé \\
\hline \multirow{4}{*}{ 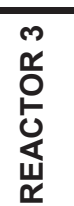 } & 50 & 36 & 0.07 & 14 \\
\hline & 50 & 18 & 0.06 & 17 \\
\hline & 50 & 12 & 0.03 & 29 \\
\hline & 50 & 8 & 0.01 & 70 \\
\hline
\end{tabular}


Click here to download Figure: Table 6.doc

Table 6. Dispersion parameters for impulse experiments with propionic acid.

\begin{tabular}{|c|c|c|c|c|}
\hline & Temperature $\left[{ }^{\circ} \mathrm{C}\right]$ & $\overline{\mathbf{t}}[\mathrm{min}]$ & $\frac{\mathrm{D}}{\mathrm{uL}}$ & Pé \\
\hline \multirow{5}{*}{$\begin{array}{l}\Sigma \\
\frac{\pi}{\alpha}\end{array}$} & 50 & 54 & 0,02 & 53 \\
\hline & 50 & 28 & 0,03 & 33 \\
\hline & 50 & 19 & 0,04 & 23 \\
\hline & 50 & 15 & 0,05 & 19 \\
\hline & 50 & 12 & 0,06 & 15 \\
\hline \multirow{5}{*}{$\begin{array}{l}\Sigma \\
\mathbf{L} \\
\mathbb{\alpha} \\
\end{array}$} & 50 & 67 & 0,04 & 28 \\
\hline & 50 & 35 & 0,05 & 22 \\
\hline & 50 & 22 & 0,05 & 20 \\
\hline & 50 & 17 & 0,06 & 17 \\
\hline & 50 & 13 & 0,07 & 14 \\
\hline
\end{tabular}


Table 7. Dispersion parameters of the different reactors at $50^{\circ} \mathrm{C}$.

\begin{tabular}{|c|c|c|c|c|c|c|c|c|}
\cline { 2 - 9 } \multicolumn{1}{c|}{} & \multicolumn{2}{c|}{ Reactor 1 } & \multicolumn{2}{c|}{ Reactor 2 } & \multicolumn{2}{c|}{ Reactor 3 } & \multicolumn{2}{c|}{ Reactor 4 } \\
\hline Flow rate [ml/min] & $\frac{\mathrm{D}}{\mathrm{uI}}$ & Pé & $\frac{\mathrm{D}}{\mathrm{uI}}$ & Pé & $\frac{\mathrm{D}}{\mathrm{uI}}$ & Pé & $\frac{\mathrm{D}}{\mathrm{uL}}$ & $\mathrm{Pé}$ \\
\hline 1 & 0.01 & 169 & 0.01 & 149 & 0.07 & 14 & 0.01 & 140 \\
\hline 3 & 0.01 & 119 & 0.01 & 130 & 0.03 & 29 & 0.02 & 59 \\
\hline 5 & 0.01 & 91 & 0.01 & 107 & 0.01 & 70 & 0.01 & 117 \\
\hline
\end{tabular}


Click here to download Figure: Table 8.doc

Table 8. Geometric parameters of the reactors.

\begin{tabular}{|c|c|c|c|}
\hline & $\varepsilon_{\mathrm{RP}}$ & As & $\overline{\mathrm{d}}_{\mathrm{P}}=\frac{6 \varepsilon_{\mathrm{RP}}[\mathrm{m}]}{\mathrm{A}_{\mathrm{s}}}$ \\
\hline Reactor 1 & 0.66 & 3485.8 & $1.14 \mathrm{E}-03$ \\
\hline Reactor 2 & 0.68 & 4431.1 & $9.24 \mathrm{E}-04$ \\
\hline Reactor 3 & 0.64 & 2797.6 & $1.38 \mathrm{E}-03$ \\
\hline Reactor 4 & 0.66 & 3517.2 & $1.12 \mathrm{E}-03$ \\
\hline
\end{tabular}


Table 9. External mass transfer parameters for reactor 1 for propionic acid

\begin{tabular}{|c|c|c|c|c|c|c|c|c|}
\hline $\begin{array}{c}\text { Flow rate } \\
\mathrm{m} / \mathrm{min}\end{array}$ & $\mathrm{Sc}$ & $\begin{array}{c}\overline{\mathrm{r}} \\
\mathrm{mol} \cdot \mathrm{m}^{-3} \cdot \mathrm{s}^{-1}\end{array}$ & $\begin{array}{c}\mathrm{k}_{\mathrm{D}} \text { from Sh from Eq.(12) } \\
\mathrm{m} / \mathrm{s}\end{array}$ & fe from Sh & $\mathrm{j}_{\mathrm{D}}$ & $\mathrm{k}_{\mathrm{D}}$ from Sh from Eq.(15) & $\begin{array}{c}\text { fe from } \mathbf{j}_{\mathrm{D}} \\
\mathrm{m} / \mathrm{s}\end{array}$ & $\mathrm{Re}_{\mathrm{P}}$ \\
\hline 2.64 & 619 & 0.77 & $1.26 \mathrm{E}-05$ & $\mathbf{0 . 0 0 2}$ & 6.44 & $2.21 \mathrm{E}-05$ & $\mathbf{0 . 0 0 1}$ & 0.36 \\
\hline 1.16 & 619 & 0.77 & $9.12 \mathrm{E}-06$ & $\mathbf{0 . 0 0 3}$ & 11.19 & $1.68 \mathrm{E}-05$ & $\mathbf{0 . 0 0 2}$ & 0.16 \\
\hline 0.90 & 619 & 0.77 & $8.32 \mathrm{E}-06$ & $\mathbf{0 . 0 0 3}$ & 13.21 & $1.55 \mathrm{E}-05$ & $\mathbf{0 . 0 0 2}$ & 0.12 \\
\hline 0.82 & 619 & 0.77 & $8.03 \mathrm{E}-06$ & $\mathbf{0 . 0 0 4}$ & 14.11 & $1.50 \mathrm{E}-05$ & $\mathbf{0 . 0 0 2}$ & 0.11 \\
\hline 0.50 & 619 & 0.77 & $6.75 \mathrm{E}-06$ & $\mathbf{0 . 0 0 4}$ & 19.75 & $1.27 \mathrm{E}-05$ & $\mathbf{0 . 0 0 2}$ & 0.07 \\
\hline
\end{tabular}


Table 10. Estimated parameters and values of standard errors at $45^{\circ} \mathrm{C}$ with $R^{2}$ :

$99.40 \%$

\begin{tabular}{|c|c|c|}
\hline Parameters & Estimated & Errors (\%) \\
\hline $\mathrm{k}_{\text {ave }}\left(\mathrm{l} \cdot \mathrm{mol}^{-1} \cdot \mathrm{s}^{-1}\right)$ & $1.4710^{-3}$ & 3.7 \\
\hline $\mathrm{Ea}(\mathrm{kJ} / \mathrm{mol})$ & 43.20 & 5.5 \\
\hline
\end{tabular}


Table 11. Estimated Parameters and Values of Standard Errors at $45^{\circ} \mathrm{C}$ with $R^{2}$ : $99.20 \%$

\begin{tabular}{|c|c|c|}
\hline Parameters & Estimated & Errors (\%) \\
\hline $\mathrm{k}_{\text {ave }}\left(\mathrm{I} \cdot \mathrm{mol}^{-1} \cdot \mathrm{s}^{-1}\right)$ & $2.1010^{-3}$ & 6.4 \\
\hline $\mathrm{Ea}\left(\mathrm{kJ} / \mathrm{mol}^{-1}\right)$ & 45.20 & 23.7 \\
\hline $\mathrm{D}_{\mathrm{a}}\left(\mathrm{m}^{2} . \mathrm{s}^{-1}\right)$ & $4.9810^{-3}$ & 28.5 \\
\hline
\end{tabular}




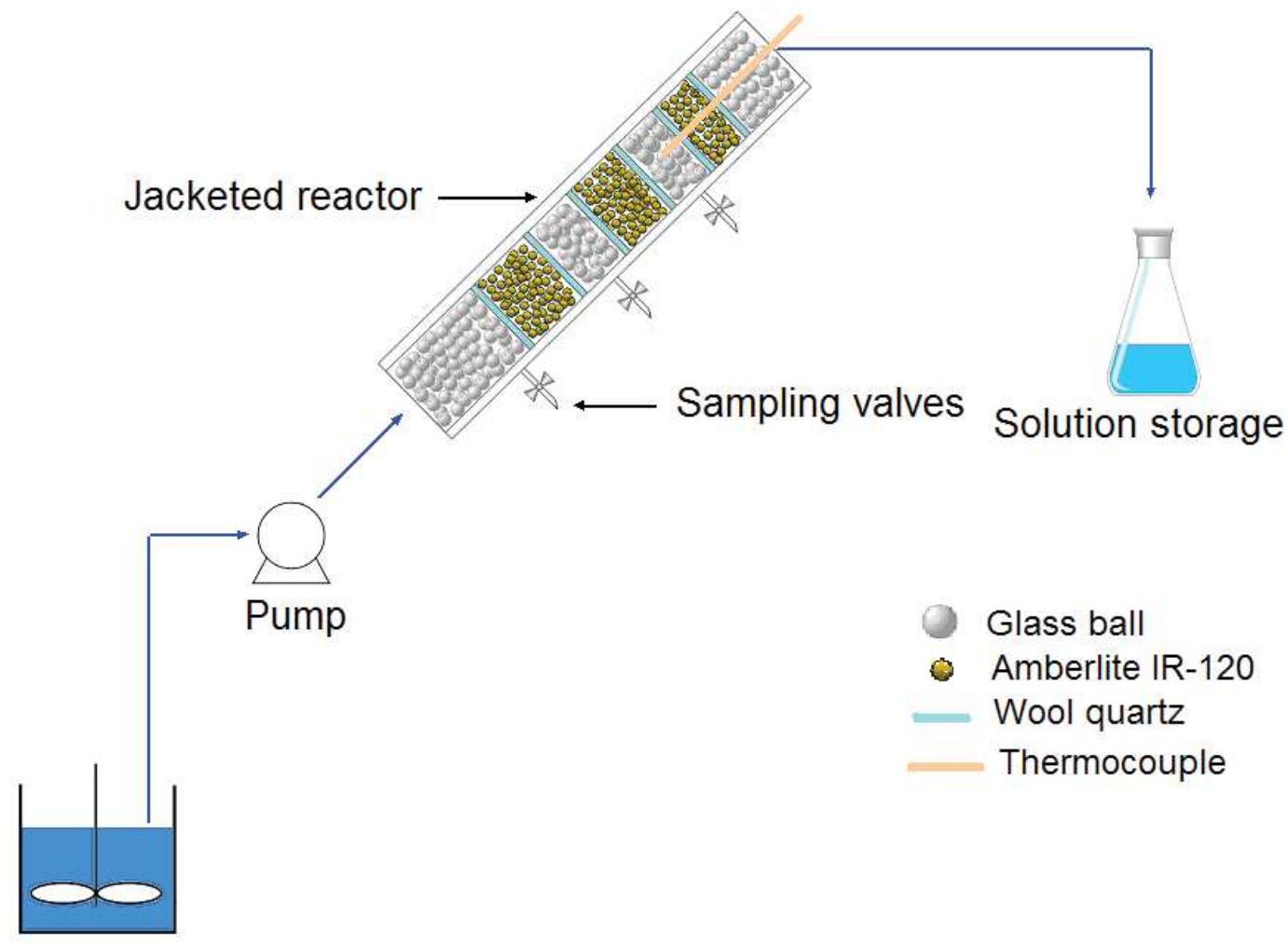

Pre-mixing carboxylic acid and hydrogen peroxide solution

Fig. 1. Experimental scheme of the continuous fixed-bed reactor for continuous peroxycarboxylic acid production. 
Click here to download Figure: Fig 2.doc

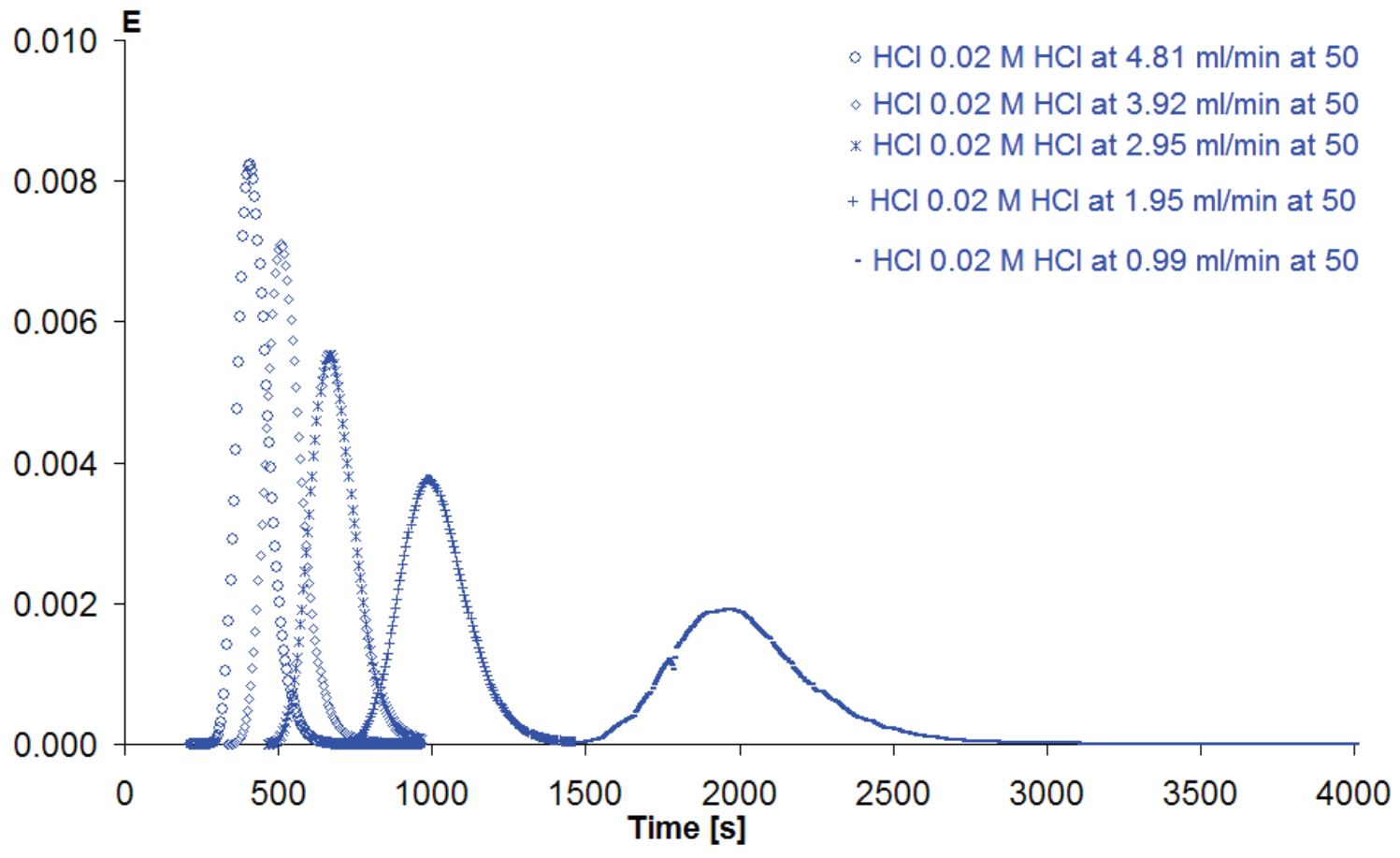

Fig.2. E-curves at $30^{\circ} \mathrm{C}$ by using $\mathrm{HCl}$ as a tracer. 


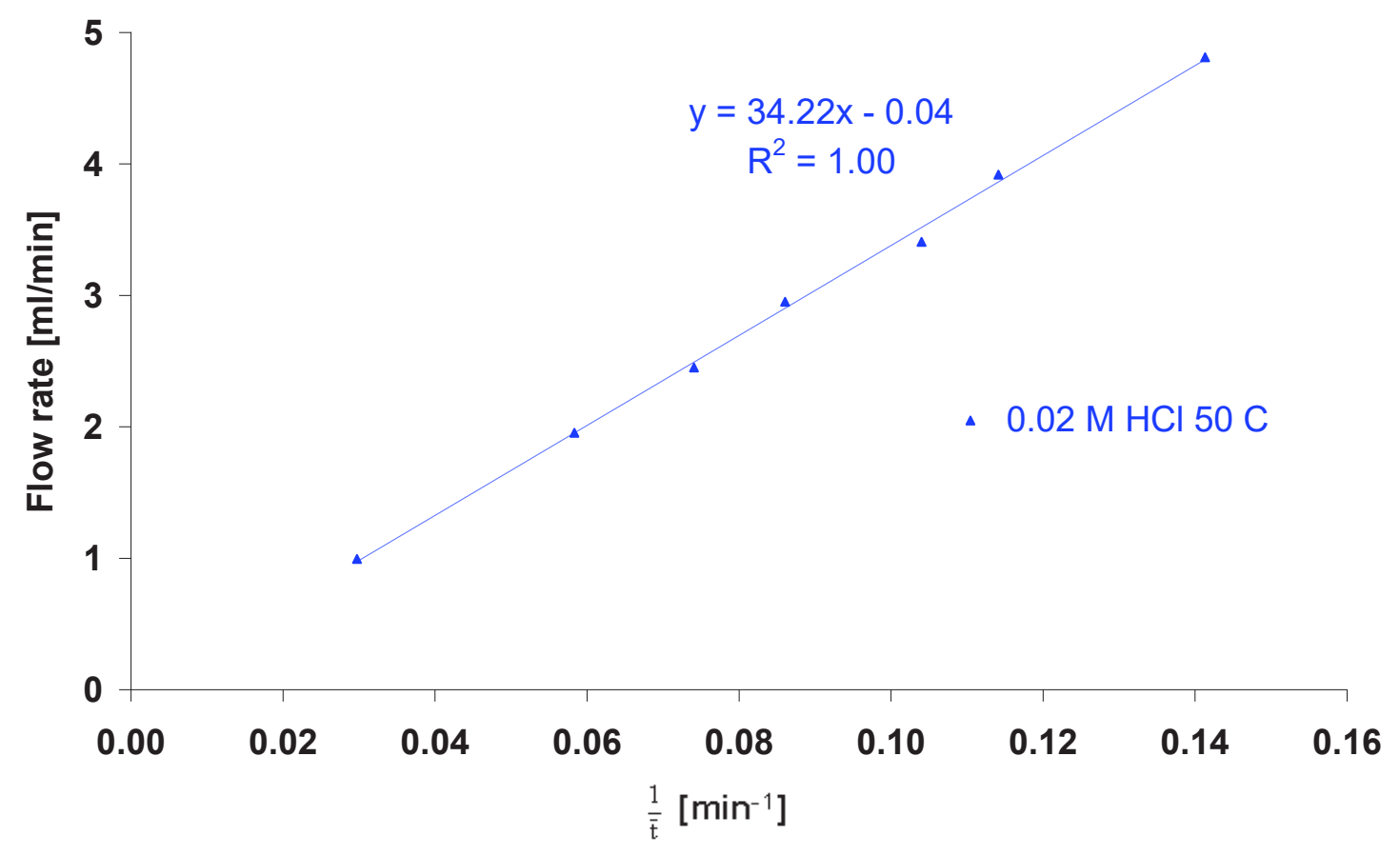

Fig. 3. Flow rate versus the inverse of the mean residence time at $50^{\circ} \mathrm{C}$ for reactor 4. 
Click here to download Figure: Fig 4.doc

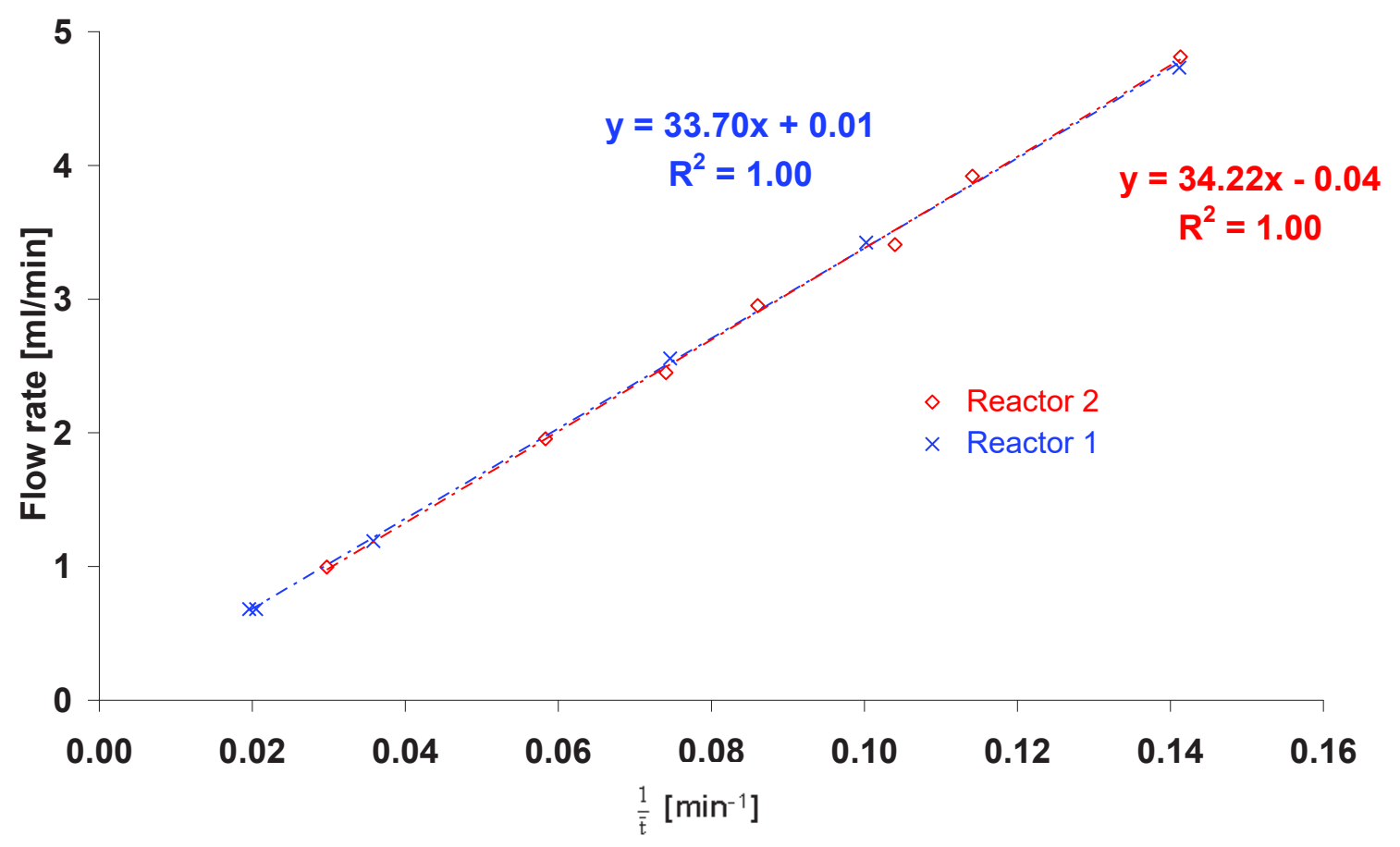

Fig. 4. Flow rate versus the inverse of the mean residence time at $50^{\circ} \mathrm{C}$. 


\section{Figure 5}

Click here to download Figure: Fig 5.doc

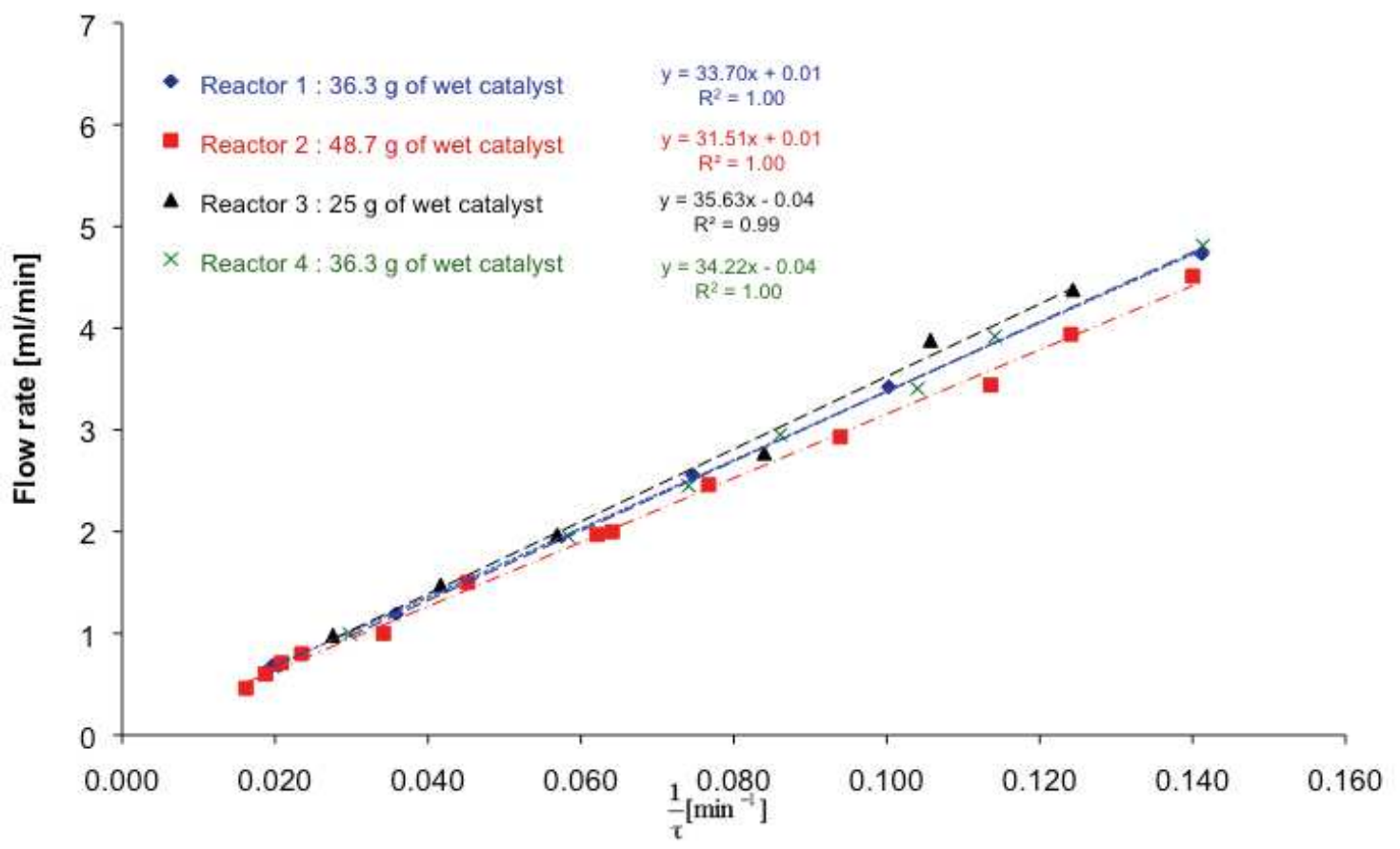

Fig. 5. Evolution of $\bar{t}$ in different reactors. 


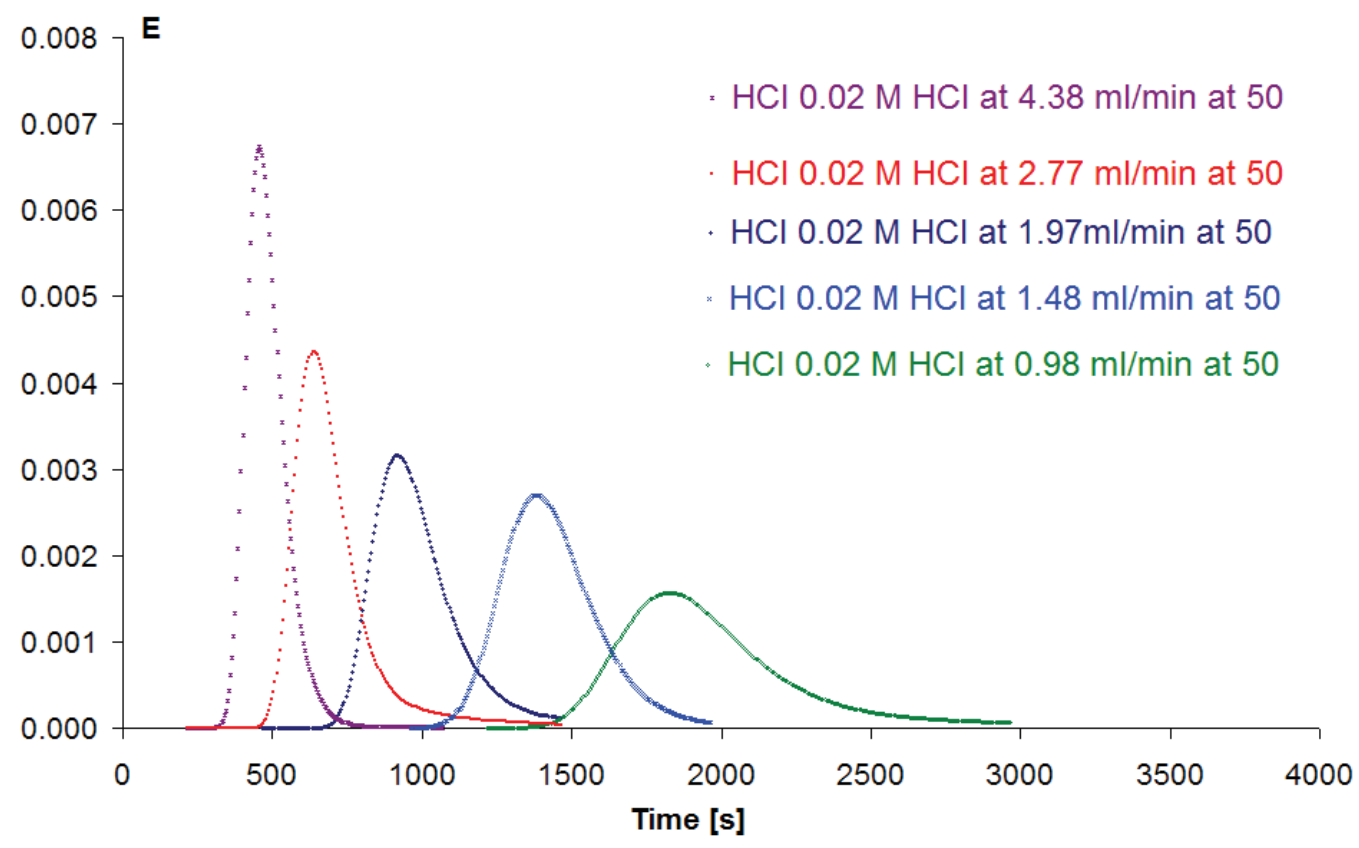

Fig. 6. E-curves for reactor 3 at different flow rates. 


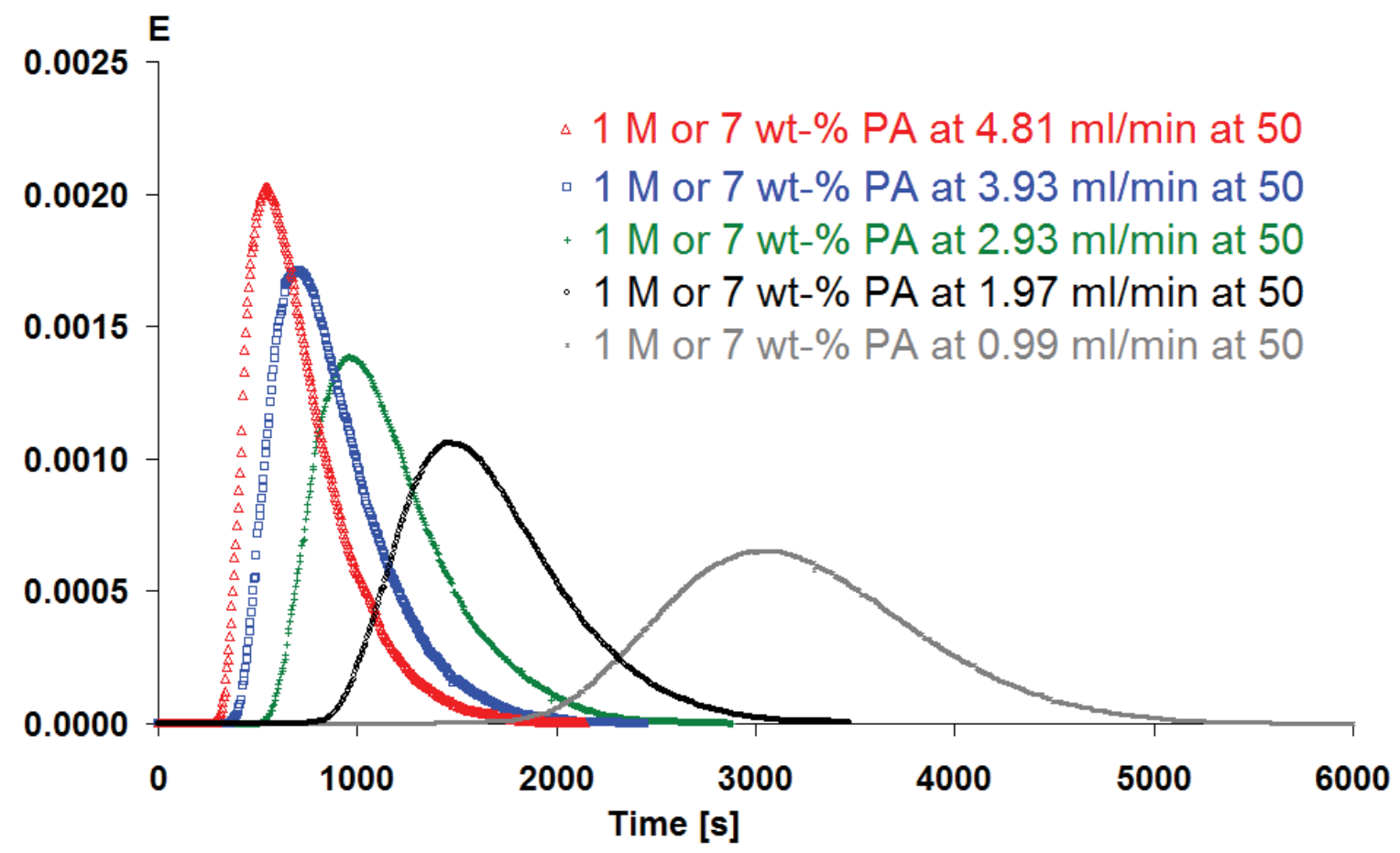

Fig. 7. E-curves for reactor 4 at $50^{\circ} \mathrm{C}$ using a $1 \mathrm{M}$ of propionic acid solution. 


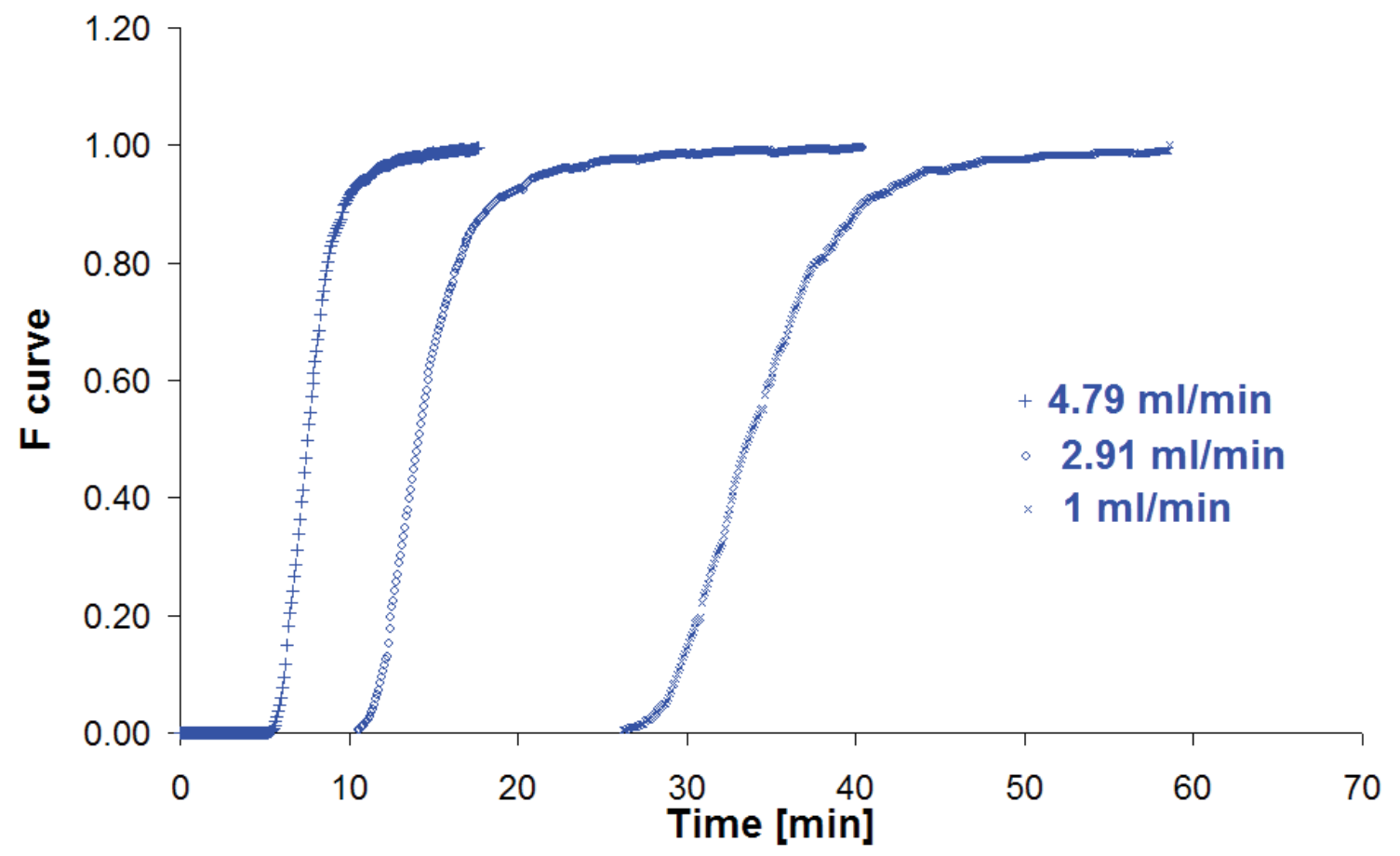

Fig. 8. F-curve for reactor 4 at $50^{\circ} \mathrm{C}$ with an $\mathrm{HCl}$ solution at $0.003 \mathrm{M}$. 


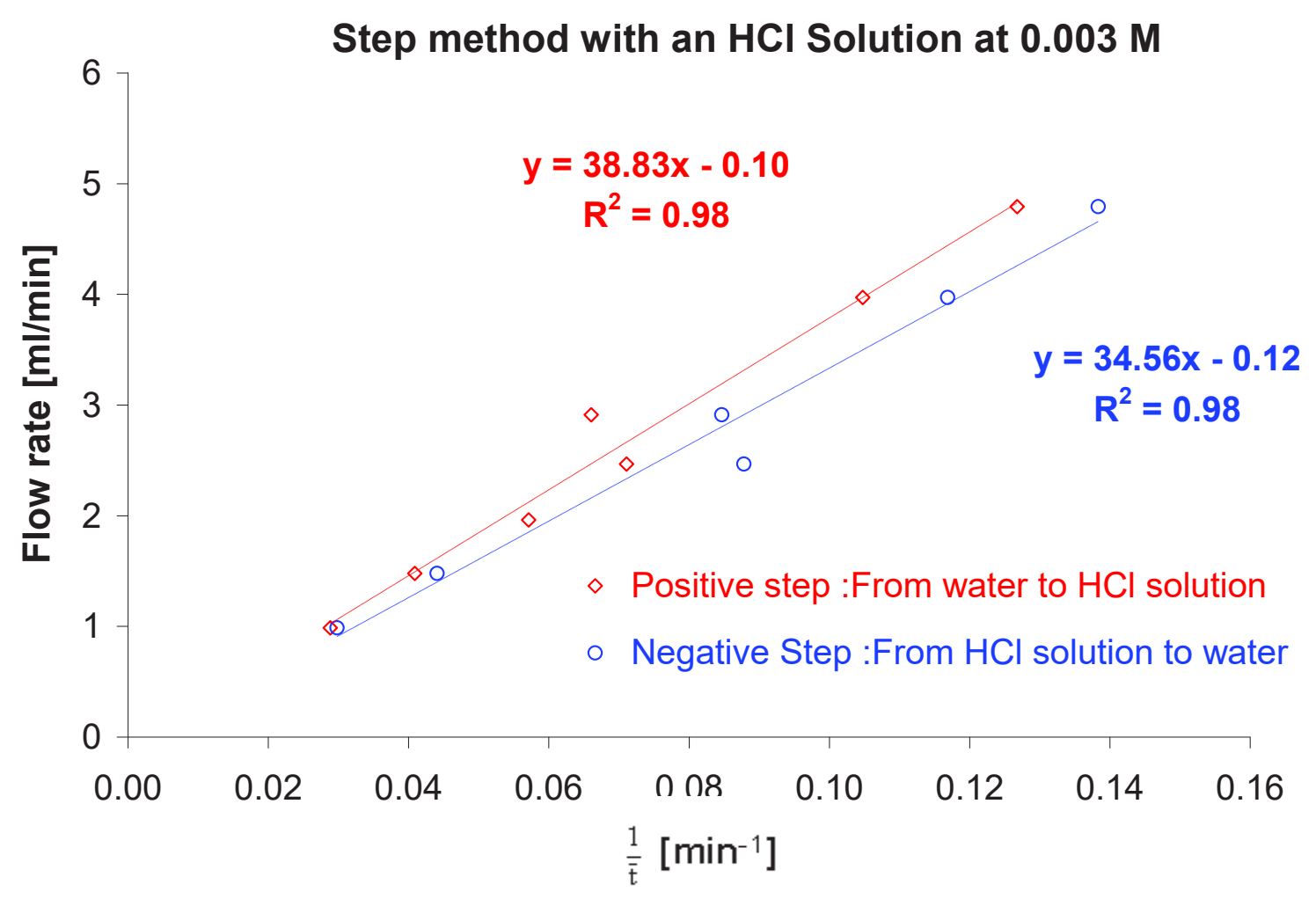

Fig. 9. Flow rate versus $\frac{1}{\overline{\mathrm{t}}}$ in the reactor 4 at $50^{\circ} \mathrm{C}$. 


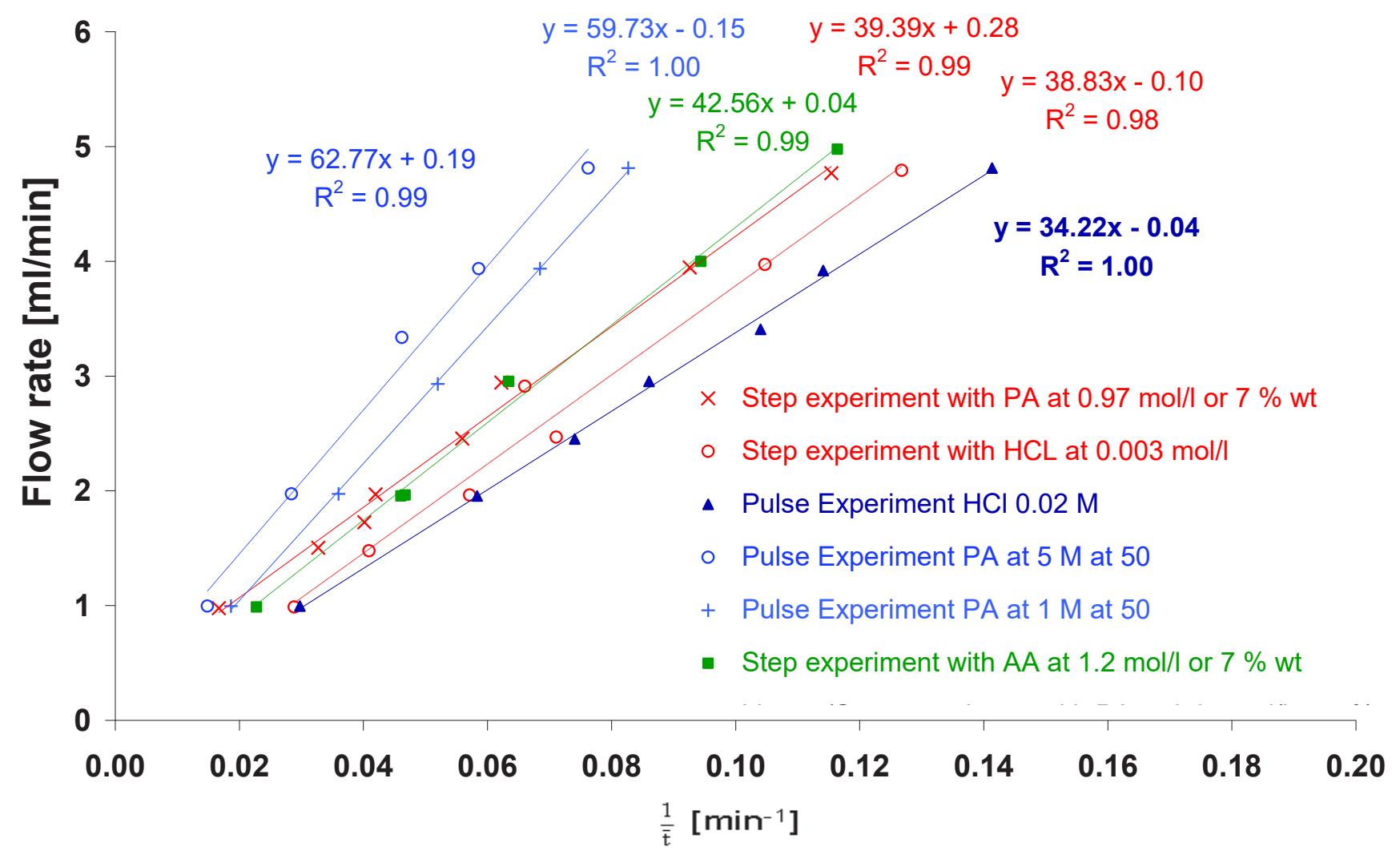

Fig. 10. Flow rate versus the reciprocal value of the mean residence time for reactor 4 at $50^{\circ} \mathrm{C}$. 


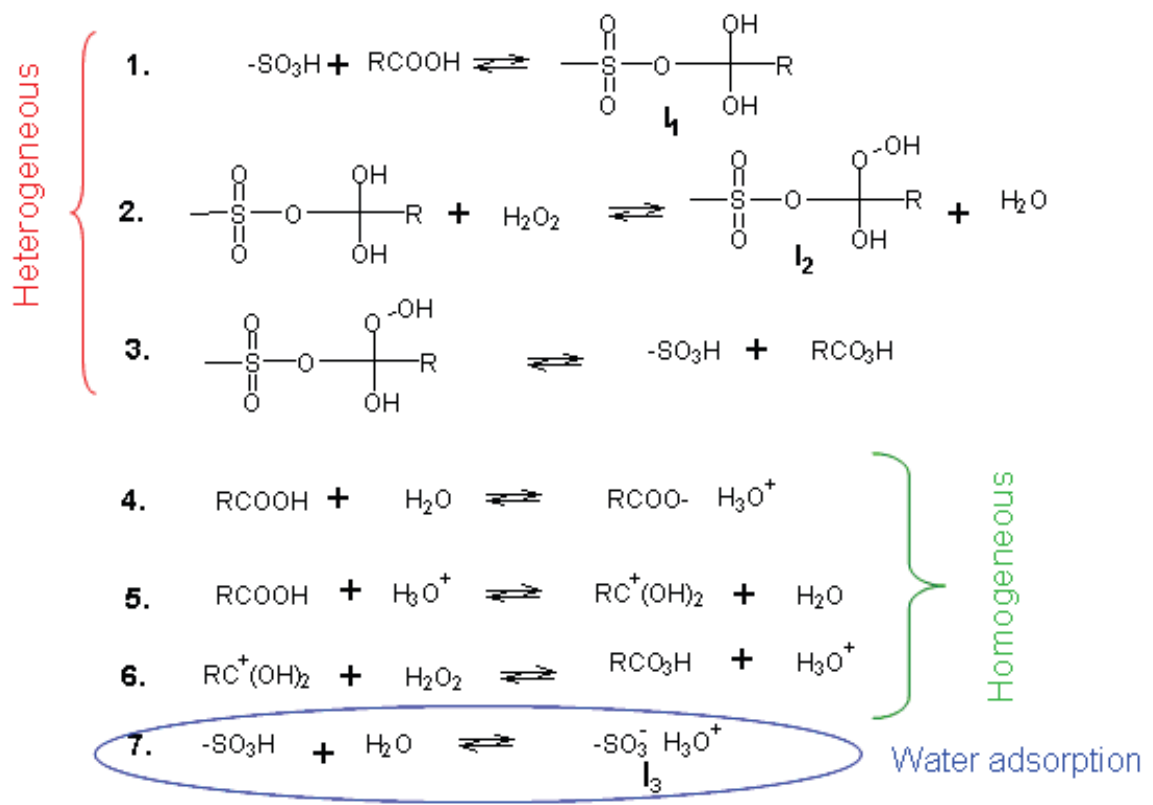

Fig. 11. Simplified mechanism for peroxycarboxylic acid synthesis by Amberlite IR120 in aqueous medium. 


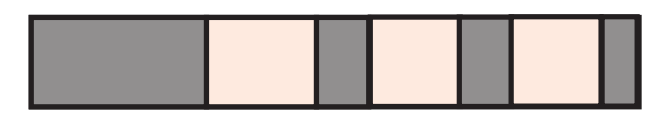

Reactor 1
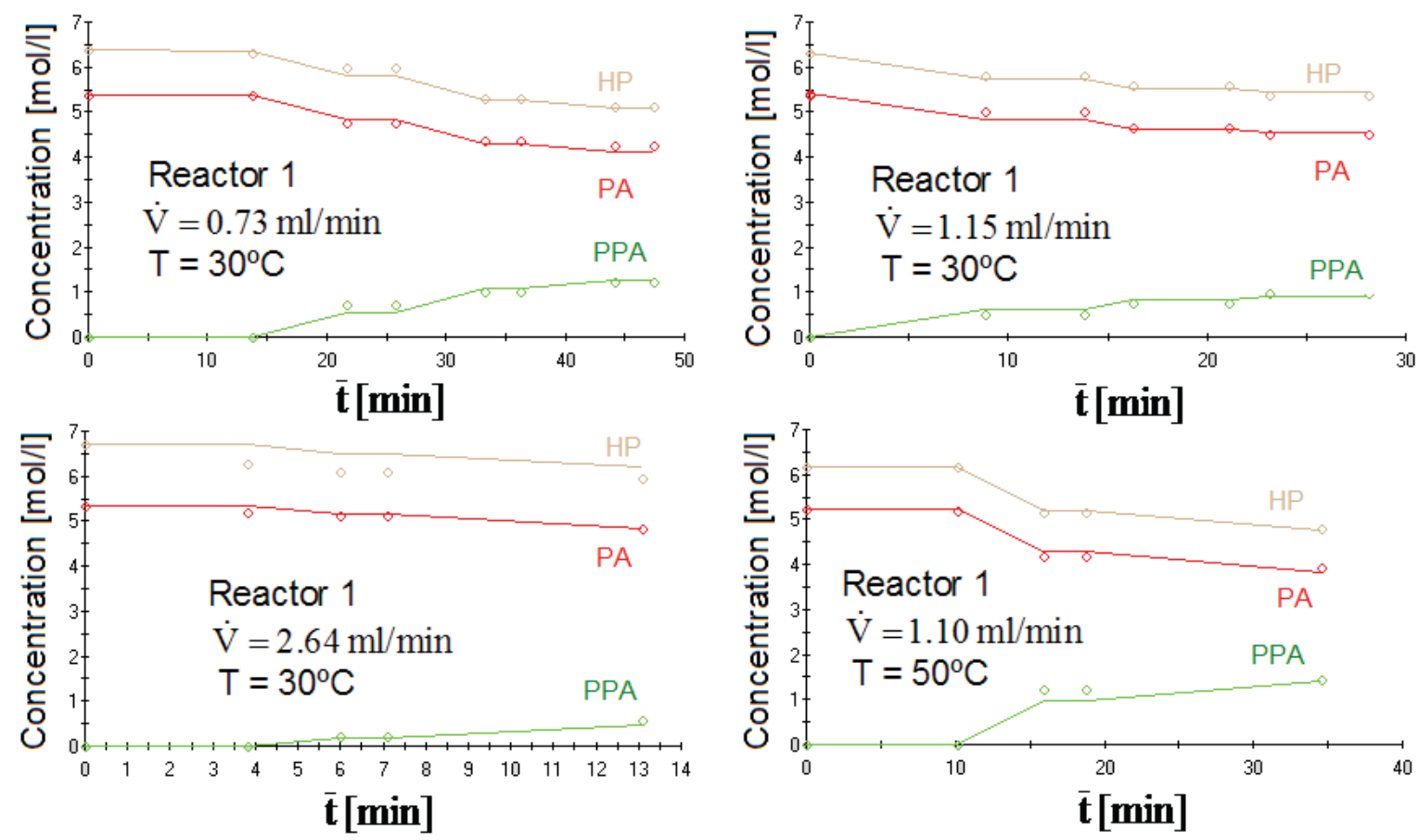

Reactor 2

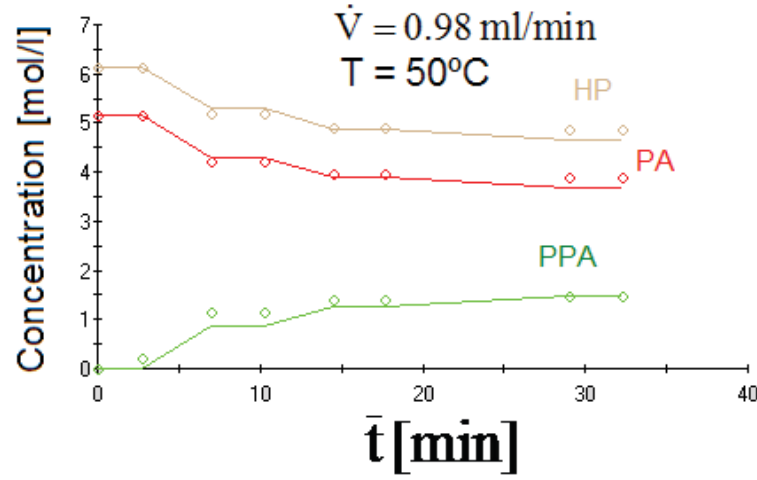

Reactor 2
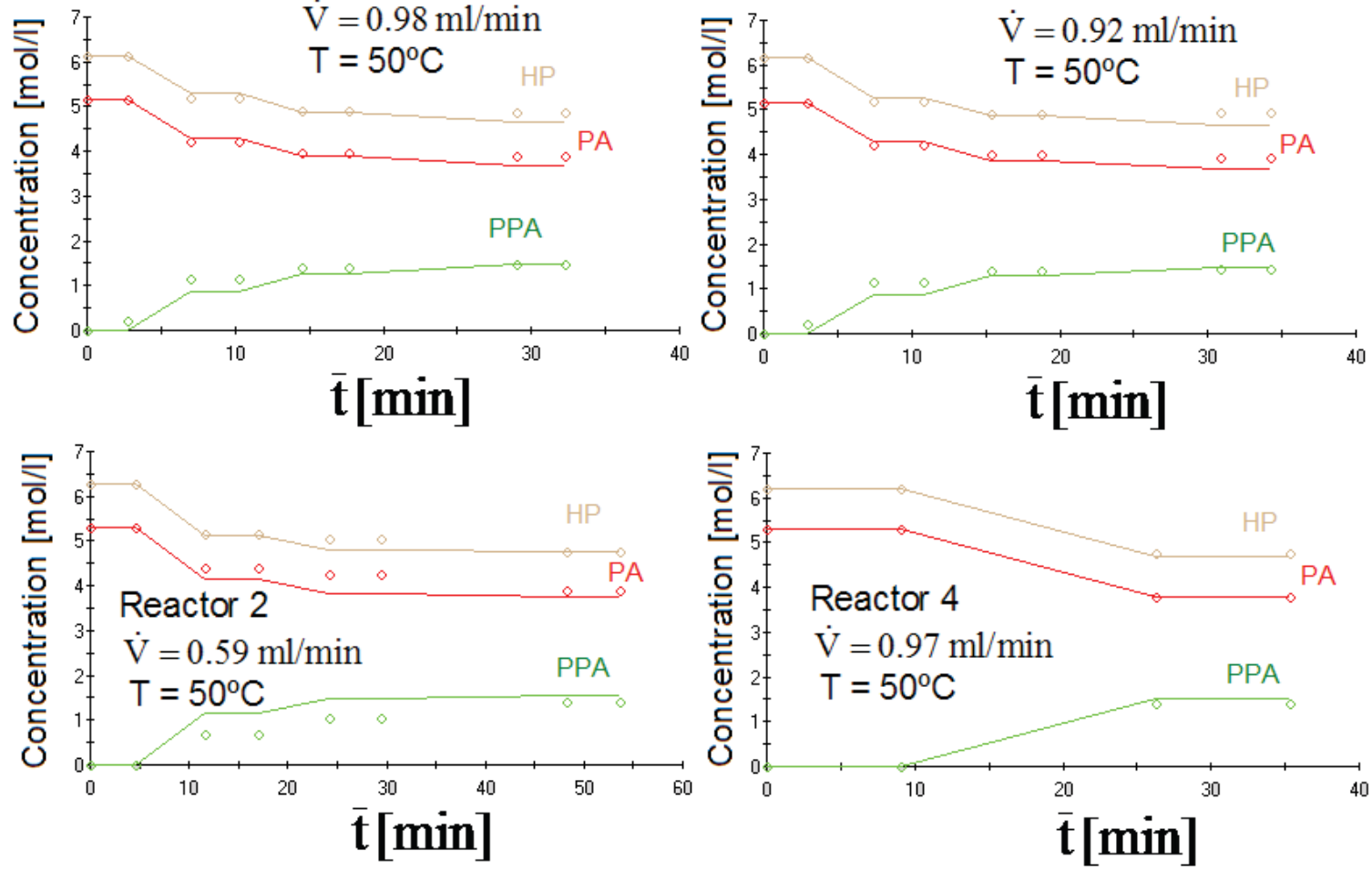

Fig. 12. Fit of the plug flow model to the perhydrolysis experiments of propionic acid. 


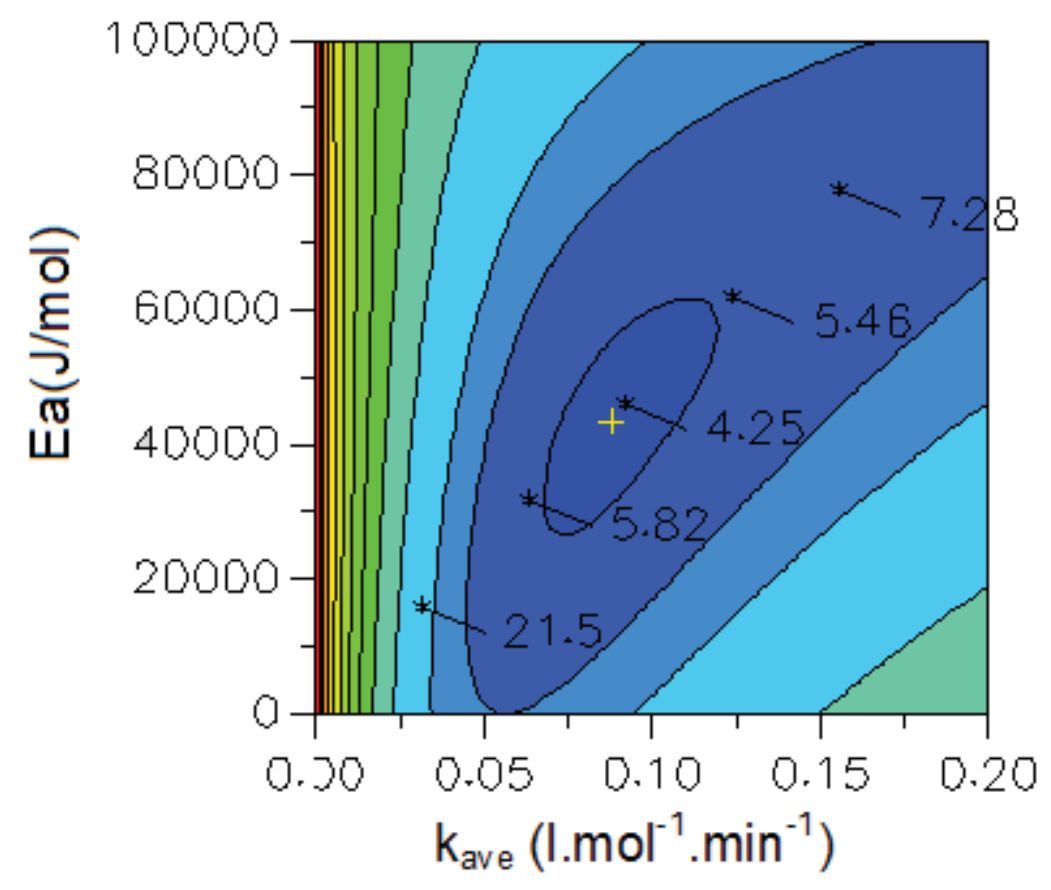

Fig. 13. Contour plot for the kinetic parameters. 

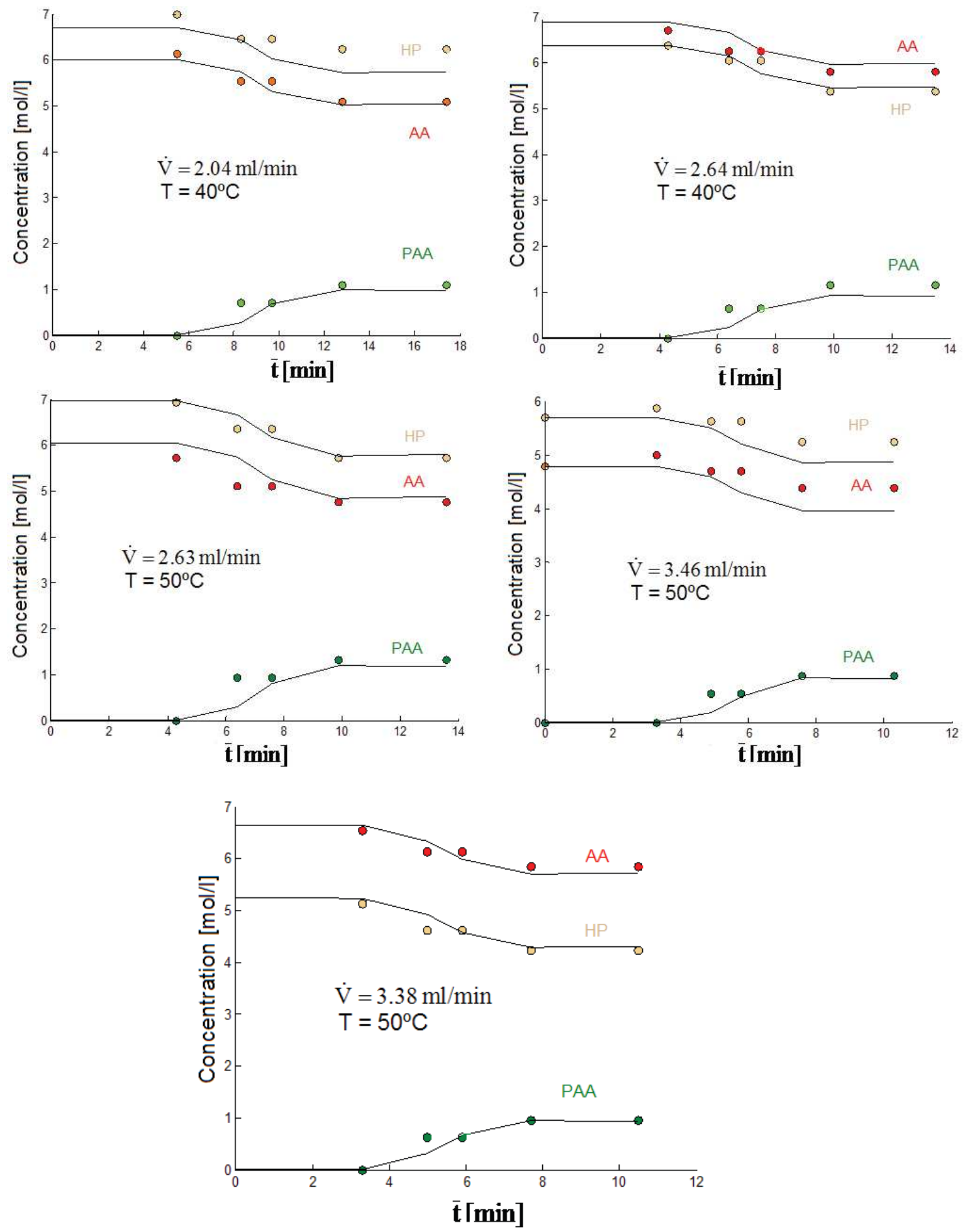

Fig. 14. Fit of the axial dispersion model to the perhydrolysis of acetic acid carried out with reactor 3 . 

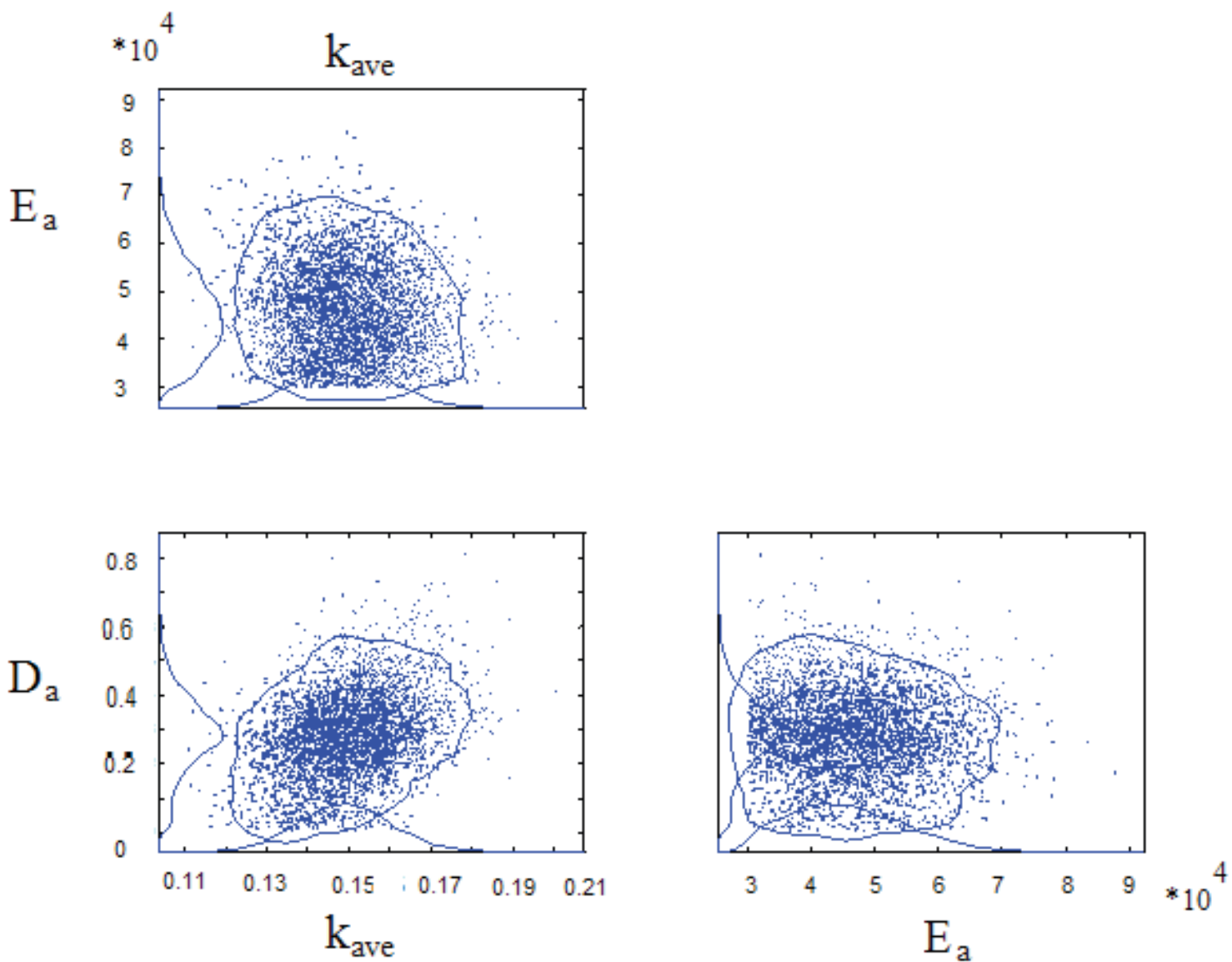

Fig. 15. Plots of the parameter sensitivity analysis (MCMC). 